\title{
OVARIAN HORMONES MODULATE ENDOTHELIN-1 RECEPTOR RESPONSES IN YOUNG WOMEN
}

by

Kelly N. Sebzda

A thesis submitted to the Faculty of the University of Delaware in partial fulfillment of the requirements for the degree of Master of Science in Exercise Science

Summer 2015

(C) 2015 Kelly N. Sebzda

All Rights Reserved 
ProQuest Number: 1602356

All rights reserved

INFORMATION TO ALL USERS

The quality of this reproduction is dependent upon the quality of the copy submitted.

In the unlikely event that the author did not send a complete manuscript and there are missing pages, these will be noted. Also, if material had to be removed, a note will indicate the deletion.

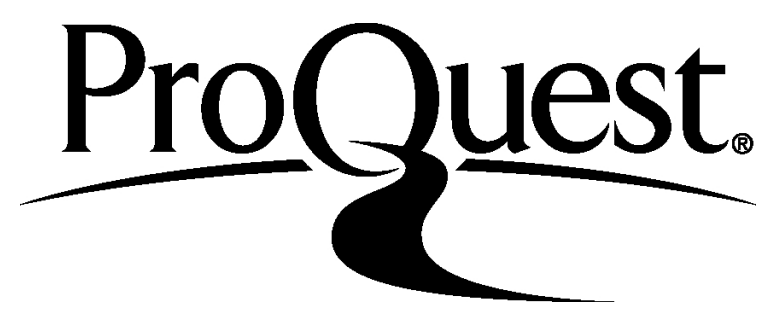

ProQuest 1602356

Published by ProQuest LLC (2015). Copyright of the Dissertation is held by the Author.

All rights reserved.

This work is protected against unauthorized copying under Title 17, United States Code Microform Edition (C) ProQuest LLC.

ProQuest LLC.

789 East Eisenhower Parkway

P.O. Box 1346

Ann Arbor, MI 48106 - 1346 


\section{OVARIAN HORMONES MODULATE ENDOTHELIN-1 RECEPTOR RESPONSES IN YOUNG WOMEN}

by

Kelly N. Sebzda

Approved:

Megan M. Wenner, Ph.D.

Professor in charge of thesis on behalf of the Advisory Committee

Approved:

William B. Farquhar, Ph.D.

Chair of the Department of Kinesiology and Applied Physiology

Approved:

Kathleen S. Matt, Ph.D.

Dean of the College of Health Sciences

Approved:

James G. Richards, Ph.D.

Vice Provost for Graduate and Professional Education 


\section{ACKNOWLEDGMENTS}

To my advisor, Megan Wenner, PhD: thank you for your continuous guidance and support throughout this project. I am extremely grateful for the opportunity to work in your lab and gain insights and feedback from you throughout this process.

To the members of my thesis committee, David Edwards, PhD and Shannon Lennon-Edwards, PhD: thank you for taking the time to be members of my committee and for all of your thoughtful input and feedback.

To my fellow lab mates and graduate students: thank you for helping me to become a better scientist and keeping me sane throughout the process. Thank you to John Guers, Andrew Kuczmarski, Meghan Ramick, Tyler Sossong, Evan Matthews, and Michael Brian for your continuous support and guidance, as well as Ken Kirschner, for making all of the cell studies possible. Thank you also to Karen Solecki, Micah Josephson, and Sophie Guderian for your ongoing support and friendship.

I would also like to extend my gratitude toward the staff at the Nurse Managed Health Center for their dedication to subject screenings and to all of our subject volunteers. Without all of you, this project wouldn't have been possible.

Finally, I would like to thank my family and friends. To my mom and Rich: thank you for your continuous support and encouragement throughout this process. You have taught me dedication and perseverance, which has helped me get through the past two years. To my sister, Jamie: thank you for bringing so much laughter into my life and for your ongoing support. And to Andy: thank you for your love and support throughout this journey, for being a shoulder to cry on, and for being my rock 
throughout all of the hard times. I have no doubt that this would not have been possible without all of your support. 


\section{TABLE OF CONTENTS}

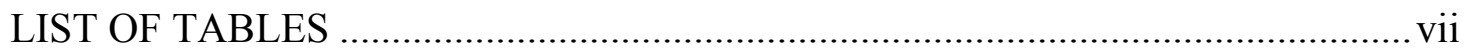

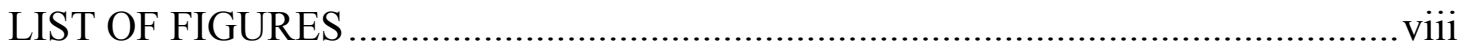

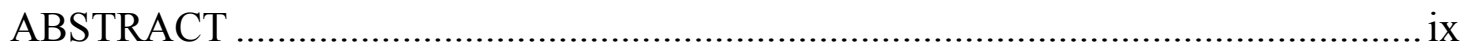

Chapter

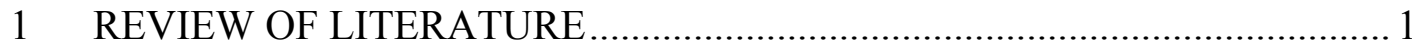

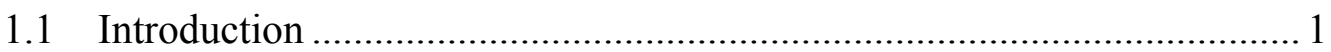

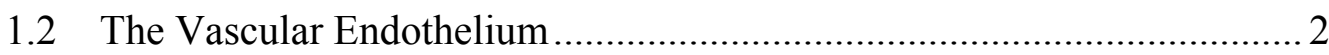

1.2.1 Techniques to Assess Endothelial Function .................................... 4

1.2.2 Hormonal Influences on Endothelial Function............................... 8

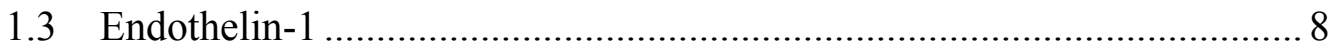

1.3.1 Endothelin-1 Concentration and Receptor Differences

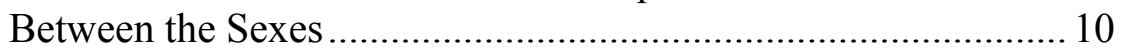

1.3.2 The Effects of Ovarian Hormones on Endothlin-1 and its

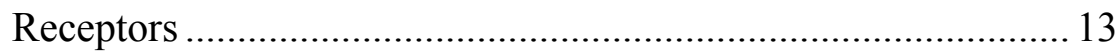

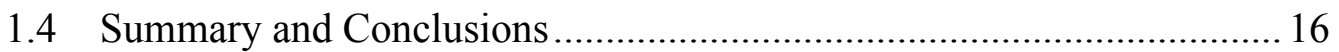

1.5 Specific Aims and Hypotheses............................................................ 17

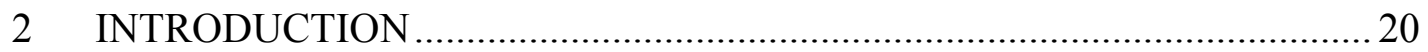

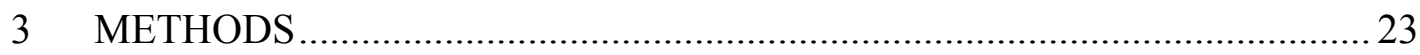

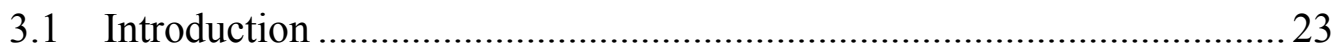

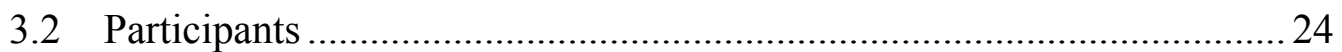

3.3 Screening Visit: Nurse Managed Health Center at the University of

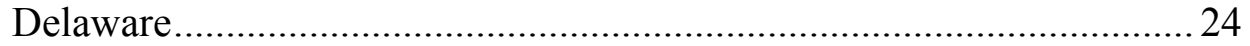

3.4 Experimental Visits: Vascular Physiology Laboratory at the University of Delaware ......................................................................... 25

3.5 Microvascular Function Assessment.................................................. 25

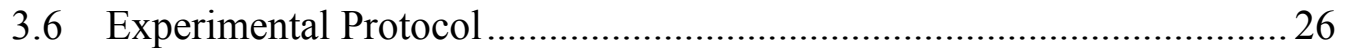

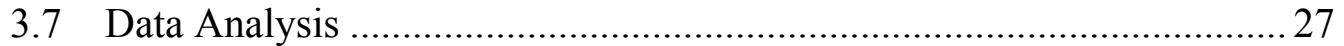

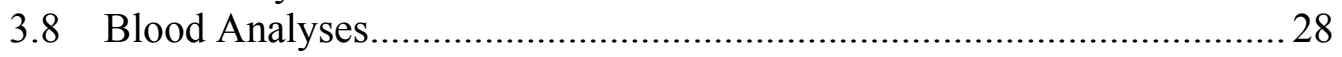




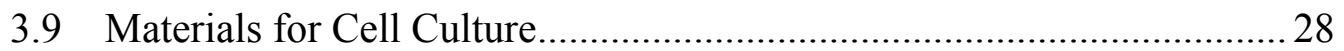

3.10 Cell Culture and Estrogen Treatment ...................................................... 29

3.11 Determination of ET-B Receptor Expression..................................... 30

3.12 Sample Size and Power Estimations ............................................. 31

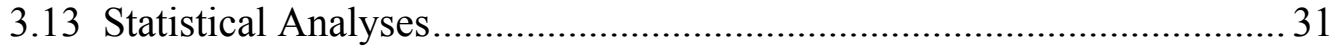

$4 \quad$ RESULTS

4.1 Subject Characteristics ............................................................... 32

4.2 Microvascular Responses to ET-1 Receptor Blockade ........................... 34

4.3 Effect of Estradiol on ET-B Receptor Expression .............................. 39

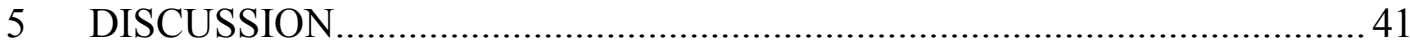

5.1 Ovarian Hormones and ET-1 Receptor Function .............................. 41

5.2 ET-B Receptor Responses to Estradiol ............................................. 44

5.3 Limitations and Future Directions..................................................... 45

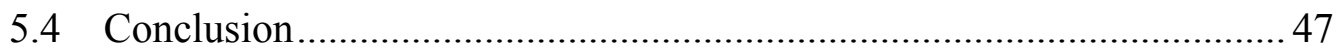

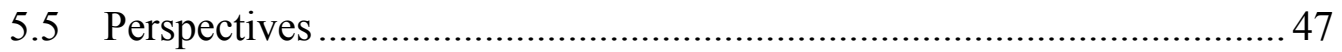

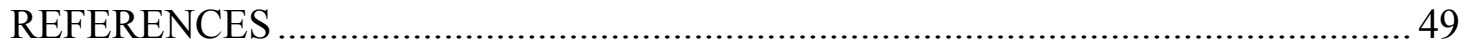

Appendix

A IRB APPROVAL LETTER …............................................................. 58

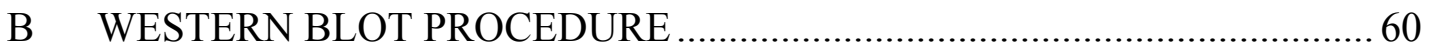




\section{LIST OF TABLES}

Table 4.1: Subject Screening Characteristics. ....................................................... 33

Table 4.2: Subject Characteristics during Experimental Visits................................ 34 


\section{LIST OF FIGURES}

Figure 1.1: Representation of ET-1 in the Vasculature ............................................. 10

Figure 3.1: Schematic of Microvascular Function Assessment Protocol...................... 27

Figure 4.1: Response to ET-B Receptor Blockade during the Mid-Luteal Phase........ 36

Figure 4.2: Response to ET-B Receptor Blockade during the Early Follicular Phase. 37

Figure 4.3: Responses to ET-A Receptor Blockade ………………………………....... 38

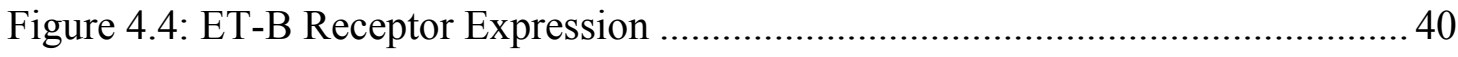




\begin{abstract}
Cardiovascular disease is the leading cause of death in women. Endothelin-1 (ET-1) is a powerful vasoconstrictor released by the endothelium, which has been implicated in the development of endothelial dysfunction and CVD. ET-1 binds to two receptor subtypes, endothelin A (ET-A) and endothelin B (ET-B). Studies in animal and cell models indicate that ovarian hormones, such as estradiol (E2) and progesterone (P4), modulate ET-1 and its receptors. However, these mechanisms have not been thoroughly examined in humans. We hypothesized that ovarian hormones mediate microvascular vasodilation through an ET-B receptor mechanism. More specifically, we expected that estradiol up-regulates ET-B receptor expression on endothelial cells. During local skin warming, we used laser Doppler flowmetry coupled with intradermal microdialysis to measure skin microcirculatory responsiveness (\% CVCmax) during ET-B antagonist infusion in women during their early follicular (EF) and mid-luteal (ML) phases $(n=8$; ages $19-22)$. We found that $\%$ CVCmax during heating tended to be lower in the ET-B blocked site compared to the control site during the ML phase $(85.3 \%$ versus $90.0 \% \mathrm{CVCmax} ; \mathrm{p}=0.07)$, but not during the EF phase (90.7\% versus $87.5 \%$ CVCmax; $p=0.22)$. This would suggest that ET-B receptors mediate vasodilation during the ML phase, when E2 and P4 are both elevated. Additionally, we treated human umbilical vein endothelial cells (HUVECs) with increasing doses of E2 for 24 hours and tested ET-B receptor expression with Western blot. We found no significant differences in ET-B receptor expression among any of the E2 doses $(p=0.7682)$. In summary, although acute E2
\end{abstract}


treatment did not alter ET-B receptor expression, our data suggest that chronic fluctuations in ovarian hormones during the menstrual cycle modulate ET-B receptor responses in women. Future studies both in young women and in our cell model will help to further elucidate the mechanism of action of E2 on ET-B receptor function and expression. This assessment of the endothelin system will continue to provide novel information on the mechanisms contributing to endothelial dysfunction in women, which will be particularly beneficial to women as they age and go through menopause. 


\section{Chapter 1}

\section{REVIEW OF LITERATURE}

\subsection{Introduction}

Cardiovascular disease (CVD) is the leading cause of death in women, with more than 400,000 women dying from CVD in 2010 (57). More women die of CVD than cancer, chronic lower respiratory disease, and Alzheimer disease combined and the total mortality is higher for women compared to men (57). Additionally, the prevalence of CVD among women is $34.0 \%$, or approximately 1 out of 3 women (57). Changes to the normal functioning of blood vessels, particularly in endothelial cells, play a large role in the development of CVD (81). Endothelial dysfunction refers to disease states in which the normal functions of endothelial cells are disturbed, "promoting vasospasm, thrombosis, intimal growth, inflammation, and plaque rupture leading to tissue ischemia, atherothrombosis and infarction" (85). Endothelial dysfunction is linked with most, if not all, CVD risk factors (7) and has been shown to precede the development of atherosclerosis $(64,80)$ and therefore contribute to the development of CVD $(18,81)$. Additionally, endothelial dysfunction has been made an independent risk factor for cardiac death, myocardial infarction, and stroke (7) and can be seen in both the macro- and microvasculature $(11,45,64,81)$.

Endothelial dysfunction has been associated with imbalances in endotheliumderived vasoactive substances, such as nitric oxide (NO) and endothelin-1 (ET-1). Notably, ovarian hormones have been shown to modulate ET-1 concentration and may contribute to functional differences in the regulation of vascular tone by the endothelin 
system. Therefore, changes in ET-1 regulation and function may contribute to endothelial dysfunction and the increased prevalence of CVD among women. Endothelial dysfunction is evident in the microvasculature, which reflects systemic vascular dysfunction and can therefore be used as a marker of CVD risk $(11,45,50)$. Microvascular dysfunction is apparent in the cutaneous microcirculation $(2,39)$ and can be studied with minimally invasive procedures, making the skin a useful model for studying the mechanisms of vascular diseases (33).

\subsection{The Vascular Endothelium}

The inner lining of blood vessels is made up of a single layer of endothelial cells, known collectively as the vascular endothelium. The endothelium functions as an interaction point between circulating blood and vascular smooth muscle cells (VSMCs) and has been described as the largest endocrine organ in the body (27, 52, 59), As such, the endothelium plays a major role in maintaining vascular homeostasis by synthesizing and releasing substances that dilate or constrict VSMCs $(27,52,59)$, assist or inhibit the formation and degradation of blood clots $(56,83)$, aid in smooth muscle proliferation (68), and maintain vascular tone $(27,56)$. Vascular tone is central to vascular health and refers to the state of contraction or relaxation of a blood vessel. The endothelium is able to maintain vascular tone through the release of several vasoactive substances, which include the relaxing factors nitric oxide (NO) $(37,59)$, endothelium-derived hyperpolarizing factor, and prostacyclin (56), and a variety of endothelium-derived contracting factors, including endothelin-1 (ET-1) (87) and thromboxane A2 $(31,52)$.

The main endothelium-derived vasodilator is NO, which plays an important role in maintaining vascular tone. In endothelial cells, NO is formed by endothelial 
NO synthase (eNOS), which converts L-arginine to citrulline and $\mathrm{NO}(4,56,65)$. NO is produced by the endothelium under basal conditions and due to physiological stimulation, such as an increase in blood flow-induced shear stress (79). NO diffuses from the endothelial cells into VSMCs, where it induces vasodilation and affects vascular tone by reducing the intracellular calcium concentration of VSMCs, thereby causing the cells to relax. When endothelial-derived NO synthesis is inhibited, either through pharmacological intervention in humans or targeted gene disruption in mice ("knock-out" mice), blood pressure rises due to increases in systemic vascular resistance, caused by widespread vasoconstriction $(34,72)$. NO also contributes to vascular tone by inhibiting platelet aggregation and leukocyte adhesion (56). Additionally, mechanisms that disrupt NO production or release contribute to endothelial dysfunction and can eventually lead to atherosclerosis (70). Therefore, due to its vasodilatory and antithrombotic characteristics, $\mathrm{NO}$ is vital to maintaining endothelial and overall vascular health.

A variety of factors, such as genetic predisposition, cardiovascular risk factors, and local factors, such as shear stress, can disrupt the normal function of the endothelium and its ability to control vascular tone. Cardiovascular risk factors, specifically, can cause an increase in oxidative stress, which results in a reduced bioavailability of $\mathrm{NO}(18,75,80)$. This is typically the result of inhibition and uncoupling of eNOS, as well as the rapid catabolism of NO by reactive oxygen species (18). Furthermore, disease states that involve endothelial dysfunction, such as atherosclerosis and hypertension, are associated with an increase in ET-1 production $(12,38)$. Both an increase in ET-1 and a decrease in NO leads to an environment in which smooth muscle cell proliferation, vascular remodeling, and inflammatory cell 
adhesion are stimulated (24). Ultimately, these changes lead to an endothelium that facilitates inflammation, thrombosis, vasoconstriction, and atherosclerotic lesion formation, characteristics of endothelial dysfunction $(18,64,81)$.

It is now well known that endothelial dysfunction is associated with most, if not all, cardiovascular risk factors (7) and precedes the development of atherosclerosis $(64,80)$. It has been made an independent risk factor for cardiac death, myocardial infarction, and stroke (7) and has been proposed as a "barometer" for cardiovascular health (81). Endothelial dysfunction has been found in both the coronary and peripheral vasculature; thus it is a systemic condition (25).

\subsubsection{Techniques to Assess Endothelial Function}

Endothelial dysfunction is evident in both the macro- and microvasculature, which reflect systemic vascular dysfunction and can therefore be used as markers of CVD risk $(11,45,50)$. There are several measurement techniques to assess vascular endothelial function, which are highly correlated with CVD risk. Each technique has the same basic notion: healthy arteries will vasodilate in response to reactive or thermal hyperemia or after pharmacological stimuli, such as infusion of endotheliumdependent vasodilators like bradykinin or acetylcholine. In diseases where endothelial dysfunction is manifested, endothelium-dependent dilation is blunted or completely absent (25). Examples of these techniques include flow-mediated dilation (FMD) to assess conduit artery responsiveness to reactive hyperemia, brachial artery infusions of acetylcholine, and laser-Doppler flowmetry (LDF) coupled with intradermal microdialysis to assess microvasculature responsiveness to thermal hyperemia and pharmacological perfusions of acetylcholine $(14,25,33,46,69,77)$. Each technique comes with its own set of advantages and disadvantages. FMD uses the brachial 
artery, which is easy to access, it is non-invasive and inexpensive, but it is technically challenging and there are needs for standardization. Brachial artery infusions also offer easy access and allow the ability to generate dose-response relationships to vasoactive substances, but they are invasive and time consuming. LDF with microdialysis also allows the ability to generate dose-response curves and is minimally invasive, but can be expensive and time intensive (25).

Recently, FMD has become the most commonly used technique to study endothelial function (25). FMD measures the ability of the brachial artery to vasodilate following an increase in luminal blood flow and endothelial shear stress (77) resulting from a period of induced ischemia. Shear stress-induced endothelial production of NO results in relaxation of vascular smooth muscle cells and subsequent vasodilation. During FMD, this is quantitatively seen as changes in the diameter of the artery occurring post-ischemia and is reported as a percent change from baseline vessel diameter, with a low percentage indicating poor endothelial function (67). Celermajer and colleagues were the first to study FMD in vivo by measuring the diameter changes of both the brachial and radial artery by ultrasound after a period of distal limb ischemia (16). Subsequent animal studies confirmed the link between increases in blood flow, wall shear stress, eNOS expression, and NO bioactivity and availability, with evidence suggesting that flow-associated shear is the physiological stimulus to endothelium-dependent vasodilation in vivo (77). This stimulus is created by a blood pressure cuff that is inflated to a supra-systolic blood pressure level for a period of five minutes and then subsequently deflated, which results in an increase in blood flow, known as reactive hyperemia. The vessel diameter is obtained through ultrasound 
image acquisition and changes in diameter can be determined through the use of edgedetection software.

While flow-mediated dilation is non-invasive and widely used, it primarily evaluates conduit artery function, thereby providing little understanding of systemic microvascular function. Therefore, the cutaneous circulation has been used as an accessible and representative vascular bed to examine the mechanisms of microvascular function $(2,39,74)$. Additionally, laser Doppler flowmetry (LDF) in combination with intradermal microdialysis is beneficial for studying the cutaneous circulation because it allows for the measurement of skin blood flow while simultaneously administering pharmacological substances to garner insight into the specific mechanisms underlying endothelial function and dysfunction. Human skin is innervated by two branches of the sympathetic nervous system: the adrenergic vasoconstrictor system, which contributes to resting vascular tone, and the cholinergic vasodilator system, which has been shown to be uninvolved in vasodilation during local heating (54). It has been shown that when the skin is heated and vasodilation occurs, it is due to the adrenergic system and is mediated by NO. When local heating to $42^{\circ} \mathrm{C}$ occurs, there is an initial spike in skin blood flow, known as the axon reflex, followed by a secondary spike and plateau that is mediated by $\mathrm{NO}(42,54,86)$. Changes in the secondary NO-mediated plateau are often seen in diseased states or as people age, suggestive of endothelial dysfunction.

Endothelial dysfunction assessed in the cutaneous microcirculation is evident in a variety of disease states. Patients with end-stage renal disease (ESRD) with either CVD or diabetes mellitus demonstrate endothelial dysfunction in the cutaneous circulation. These patients have a decrease in the thermal peaks and plateau in 
response to thermal hyperemia and a decrease in the area under the curve during reactive hyperemia compared to the healthy controls. These measurements are indicative of endothelial cell dysfunction and are able to be detected through the noninvasive method of LDF in the cutaneous microvasculature (74). In addition, thermal hyperemia indices correlate with Framingham risk in patients with ESRD. Patients with ESRD and a high Framingham risk have significantly decreased first and second thermal peaks compared to those with a low Framingham risk (45). Similar results were reported by Ijzerman et al. (2003), which found that individuals at increased risk for coronary heart disease (CHD) are characterized by an impaired cutaneous microvascular function. Through iontophoresis of acetylcholine and sodium nitroprusside coupled with LDF, they found that with increasing CHD risk, endothelium-dependent and -independent vasodilation decreased (39). Together, this would suggest that assessing the microcirculation is a sensitive measure of CVD risk. Therefore, measuring microvascular function in the cutaneous circulation is a valid, minimally invasive method to study microvascular function associated with CVD and the coronary circulation.

In addition to studying overall endothelial function, the cutaneous circulation provides a good model for studying the effects of ET-1 and its antagonists on the cutaneous microcirculation. Through a variety of techniques, it has been shown that ET-1 is present in the human skin and works as a potent vasoconstrictor on the cutaneous microcirculation $(8,9,17,76)$. Additionally, both ET-A and ET-B receptors are also present in the human skin and play a role in maintaining cutaneous vascular tone (51). While there have been several experiments studying the effect of ET-1 and its receptors on microvascular function, many do not take into account the effects of 
sex hormones on ET-1 production and function. Therefore, this study looked specifically at women during two phases of the menstrual cycle, in order to understand the impact of ovarian hormones on the endothelin system.

\subsubsection{Hormonal Influences on Endothelial Function}

FMD values have been shown to demonstrate sex differences (49), which are believed to be due to differences in ovarian hormones. In women, FMD is lowest during the early follicular phase (low estrogen and progesterone) and the administration of estradiol results in an increased FMD, compared to hormonesuppressed values $(22,29)$. A study by Miner and colleagues looked at changes in FMD in healthy, premenopausal women when they were given oral progesterone alone, transdermal estrogen alone, and progesterone and estrogen combined after hormone suppression (10-12 days of gonadotropin-releasing hormone antagonist administration) (53). They found that there were significant differences in FMD between the hormone suppression and estrogen only supplementation, with values being higher (better) after estrogen treatment. These increases were blunted when oral progesterone was also supplemented, and there were no differences found between the hormone suppression and progesterone only supplementation (53). This would suggest that estrogen is the ovarian hormone responsible for improved endothelial function, as indexed by FMD.

\subsection{Endothelin-1}

The main endothelial-derived vasoconstrictor is ET-1, which was first discovered by Yanagisawa et al., (1988) and has been described as the most potent mammalian vasoconstrictor known to date. As reviewed by Kohan et al., ET-1 is 
produced when endothelin-converting enzyme (ECE) cleaves "big ET-1" in endothelial cells (44). ET-1 is then secreted abluminally and acts as a local paracrine and autocrine factor by binding to G-protein-coupled receptors on vascular smooth muscle and endothelial cells $(35,82)$. The two main types of ET-1 receptors are endothelin receptor A (ET-A) and endothelin receptor B (ET-B). In the vasculature, ET-A receptors are located on the smooth muscle, while ET-B receptors are found on both endothelial cells and VSMCs (21). When ET-1 binds to either receptor on VSMCs, it mediates vasoconstriction and cell proliferation, while ET-B receptors on the endothelium facilitate vasodilation through the stimulation of eNOS $(21,43,44)$. The mechanism of action of ET-1 in the vasculature can be seen in Figure 1.1. Importantly, ET-1 has been shown to contribute to endothelial dysfunction and has been implicated in the development of atherosclerosis $(5,19,38)$; therefore, ET-1 was the main protein of interest for this study. 


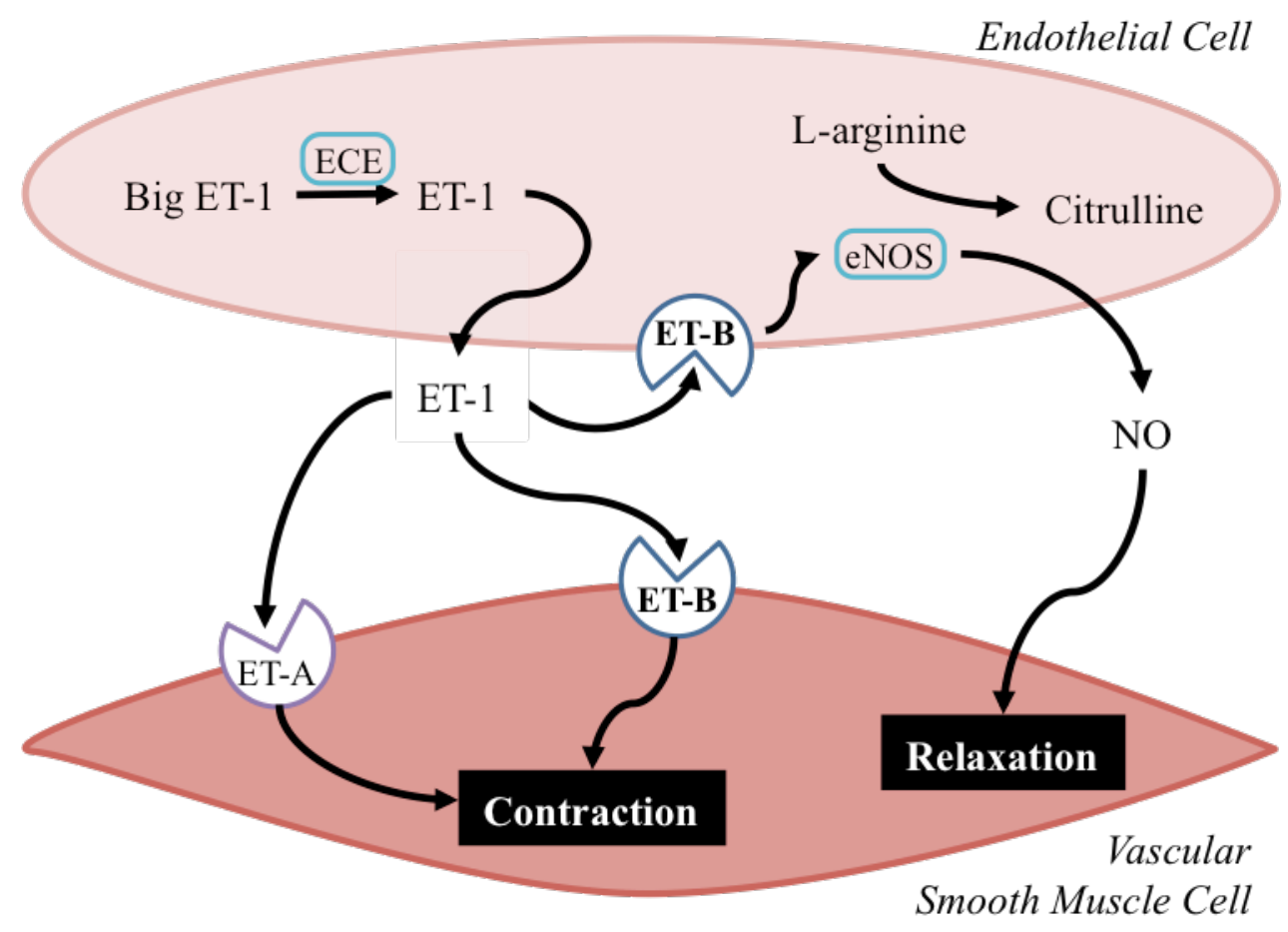

Figure 1.1: Representation of ET-1 in the Vasculature. Abbreviations: Big ET-1, big endothelin-1; ET-1, endothelin-1; ECE, endothelin-converting enzyme; ET-A, endothelin receptor A; ET-B, endothelin receptor B; eNOS, endothelial nitric oxide synthase; NO, nitric oxide; E2, 17ßestradiol; P4, progesterone.

\subsubsection{Endothelin-1 Concentration and Receptor Differences Between the Sexes}

Plasma ET-1 concentration has been shown to differ between the sexes. An important study by Polderman et al. sought to determine whether a sex-associated difference in endothelin concentration exists and whether any difference is influenced by sex hormones (62). The subjects involved were healthy men and women, pregnant women, and male-to-female and female-to-male transsexual patients both before and during cross-gender hormone treatment, which involves administration of testosterone esters to women and ethinylestradiol and cyproterone acetate to men (62). They found that plasma ET-1 levels were significantly higher in men compared to women and in 
non-pregnant controls compared to pregnant women. This would suggest that high levels of estradiol and progesterone associated with pregnancy are also associated with low ET-1 concentrations. Furthermore, in the transsexual patients, men receiving estradiol and cyproterone acetate had lower ET-1 levels post-treatment and women receiving testosterone had higher ET-1 levels post-treatment (62). Thus, it can be concluded that endothelin levels are higher in men than in women and that the difference is mediated by sex hormones (62).

Additionally, there are sex differences in the function of the endothelin system. Ergul et al. examined the presence of ET-A and ET-B receptors on human saphenous veins from older men and women undergoing bypass surgery (21). Through saturation receptor binding experiments, they demonstrated that the density of ET receptors is different in men and women, with women having fewer ET receptors overall. Additionally, women have a different ET-A:ET-B ratio compared to men (50:50 versus 75:25, respectively). Additionally, through vascular reactivity, they demonstrated that ET-1-induced vasoconstriction is mediated by ET-A receptors, as evidenced by the complete blockade of the ET response by BQ-123, an ET-A selective receptor antagonist (21).

A more recent study found similar physiological differences between young men and women with regard to ET-B receptors, by monitoring skin blood flow (SkBF) in young men and women before, during, and after administration of BQ-788, an ETB selective antagonist (43). The purpose of the study was to determine whether the contribution of ET-B receptors to resting vascular tone differs between the sexes. They studied 11 men and 11 women, and showed that with administration of BQ-788, blood flow increases in young men, indicating that ET-B receptors in the cutaneous vessels 
of men mediate vasoconstriction. Conversely, infusion of BQ-788 reduced blood flow in women, demonstrating that ET-B receptors of women mediate vasodilation (43). However, one limitation of this study is that there was no control over circulating ovarian hormones in the women, since they did not test the women at specific points in their menstrual cycle. Therefore, even though this study demonstrates a sex difference in ET-B receptor function, it is unclear if these differences are due to ovarian hormones or another mechanism.

A study by Stauffer and colleagues found similar differences between middleaged and older adults (73). They hypothesized that older men would demonstrate a greater ET-1-mediated vasoconstrictor tone compared to older women, which they tested by measuring forearm blood flow (FBF) via strain-gauge venous occlusion plethysmography (73). They tested healthy, sedentary middle-aged and older adults (ages 45-71), who were not obese, non-smokers, normotensive, and non-medicated. All women were at least 1 year post-menopausal and were not taking hormone therapy. They tested FBF at rest and then after ET-1 receptor blockade with either BQ123 (ET-A receptor antagonist) or a combination of BQ-123 and BQ-788 (ET-B receptor antagonist). The study found that FBF responses to the ET-A receptor blockade were significantly different between the sexes, with men showing a substantial increase in FBF, while the increase in women was more moderate. During the combination blockade, women showed a further increase in blood flow, while the men did not. This suggests that older men demonstrate greater ET-A-mediated vasoconstrictor tone, whereas older, post-menopausal women demonstrate greater ETB-mediated vasoconstrictor tone (73). These findings taken together with those from Kellogg et al. (43) suggest that premenopausal women, who have higher circulating 
levels of ovarian hormones, show ET-B-mediated vasodilator tone, whereas older, post-menopausal women without ovarian hormones show ET-B-mediated vasoconstrictor tone. Overall, this suggests that the changes in ovarian hormones are affecting the function of ET-B receptors. However, Kellogg et al. (43) did not take menstrual phase into account, so it is unclear which ovarian hormone is actually playing the role in this difference.

\subsubsection{The Effects of Ovarian Hormones on Endothlin-1 and its Receptors}

Ovarian hormones have been shown to modulate ET-1 and its receptors. ET-1 concentration also changes throughout the menstrual cycle in healthy, young women. Polderman et al. tested 16 healthy premenopausal women during three different phases of a spontaneous menstrual cycle: the menstrual phase (days 1-3), the follicular phase (days 9-12), and the luteal phase (days 20-23) (63). Eight women were not using oral contraceptives (OCs), while the other eight were using monophasic OCs. For the women not using OCs, ET-1 levels fluctuated significantly throughout the menstrual cycle. ET-1 concentration was significantly higher during the menstrual phase, when estradiol and progesterone levels are the lowest, compared to the follicular and luteal phases $(\mathrm{p}<.01)$. There was no significant fluctuation, however, in the women using OCs, suggesting that ET-1 is modulated by varying levels of ovarian hormones in nonOC users (63).

Functional differences in the endothelin system have also been shown to be modulated by ovarian hormones. While both progesterone and estradiol fluctuate during the menstrual cycle, it has been shown that $17 \beta$-estradiol (E2), specifically, is at least partly responsible for changes in ET-1 expression in human endothelial cells. Bilsel et al. studied the effect of E2 on ET-1 gene expression and basal release from 
human umbilical vein endothelial cells (HUVECs) (6). The cells were incubated with either estrogen-free medium or medium containing $10^{-9}$ or $10^{-7} \mathrm{M}$ E2 for 48 hours. Northern blot analysis demonstrated that incubation with $10^{-9}$ and $10^{-7} \mathrm{M} \mathrm{E} 2$ for 48 hours caused a $30 \%$ and $47 \%$ inhibition of ET-1 mRNA expression, respectively (6). Additionally, after 6 hours of HUVEC incubation with or without E2, radioimmunoassay showed significantly lower ET-1 concentration in the incubated cells versus those in the E2-deprived media (6). A different in vitro study by Juan et al. reported similar findings (41). When female HUVECs were treated with E2, but not 17 $\alpha$-estradiol, there was an inhibition of strain-induced ET-1 gene expression and peptide secretion (41). Taken together, 17ß-estradiol down-regulates both ET-1 mRNA expression and release from HUVECs, though it remains unclear if E2 also independently modulates ET-1 receptor expression on endothelial cells.

There are a few animal studies that aimed to determine how E2 affects ET-1 receptor regulation; however, there haven't been any studies in humans or human endothelial cells to date. Nuedling et al. investigated the regulation of endothelin receptor expression in the hearts of female spontaneously hypertensive rats with respect to E2 levels (58). Animals that had been ovariectomized had a significant upregulation of the ET-B receptor mRNA and protein expression in the left ventricular myocardium, which was completely inhibited by E2 replacement (58). These data indicate that estrogen regulates the expression of the ET-B receptor in rat ventricular myocardium. A study by Pedersen et al. investigated the effects of E2 on the ET-B receptor in coronary arteries from ovariectomized hyperlipidemic rabbits (60). There was a significant increase in ET-B mRNA expression in rabbits receiving oral treatment of E2 for 16 weeks, compared to animals receiving a placebo or E2 with a 
progestin (60). These data suggest that long-term E2 treatment up-regulates the expression of ET-B receptors in the coronary arteries of hyperlipidemic rabbits. Altogether, these studies indicate that E2 modulates the expression of the ET-B receptor, down-regulating its expression in myocardial cells, while up-regulating its expression in coronary arteries, which contain both smooth muscle and endothelial cells. However, the independent effect of E2 on ET-B receptor expression in endothelial cells alone has not been investigated.

While this literature would suggest that ovarian hormones impact ET-B receptor regulation and function, there have been few, if any, study that have examined the impact of ovarian hormones on ET-receptor control of vascular function in humans. One such study by Wenner and colleagues aimed to examine the receptor mechanism by which ET-1 influences cutaneous microvascular function in women with and without polycystic ovary syndrome (PCOS), a disease characterized by an altered hormonal profile (84). This study tested otherwise healthy women with and without PCOS using a laser Doppler flowmetry coupled with microdialysis. After the resting period, the microdialysis fibers were perfused with either BQ-123 (ET-A antagonist) or BQ-788 (ET-B antagonist) over a variety of doses. After the blocker infusion period, the local heaters were set to $42^{\circ} \mathrm{C}$ to evaluate differences in vasodilation. Finally, SNP was perfused to induce a maximal vasodilation, to determine maximal SkBF (84). Their data indicate, in both groups, that with increasing doses of BQ-123, there was a dose-dependent increase in SkBF and vasodilation. In contrast, with increasing doses of BQ-788, there was a dosedependent decrease in SkBF, and therefore vasoconstriction. Furthermore, this doseresponse curve was shifted to the right in women with PCOS, which is indicative of 
reduced ET-B-mediated vasodilation (84). This is important because it suggests that women with PCOS, who have a unique hormonal profile (non-fluctuating levels of E2 and P4 and elevated androgens), could be at a higher risk for developing CVD due to the differences in ET-1 receptor function. While the women in this study were part of a patient population, it is the only study in humans to examine ET-1 receptor control of vascular function. Additionally, the information on the dose-response relationship for the ET-B antagonist is what will guide our BQ-788 dose in this study.

\subsection{Summary and Conclusions}

Because ET-1 has been implicated in the pathogenesis of vascular dysfunction and CVD, and because there are sex differences in both the endothelin system and in the prevalence of CVD, understanding the role ovarian hormones play in contributing to these differences is essential, physiologically and clinically. While the literature suggests that these differences may be due to ovarian hormones, there have been limited studies looking at the effect of E2 on ET-B receptors function in vivo and to our knowledge, none examining its effects in vitro. Therefore, this study aimed to examine the differences in the endothelin system related to fluctuating estradiol and progesterone levels. Specifically, this study aimed to understand how estradiol affects ET-B receptor function and expression on endothelial cells, since these are the receptors responsible for the cardioprotective vasodilation of the macro- and microcirculation. While we studied these receptors in healthy, young women and in vitro, identifying the mechanisms and pathways that contribute to the sex differences in ET-B receptor function is important to develop preventative strategies for women as they age, go through menopause, and lose the cardiovascular protective mechanisms related to circulating ovarian hormones. 


\subsection{Specific Aims and Hypotheses}

Cardiovascular disease (CVD) is the leading cause of death in women (57). The endothelium plays a central role in maintaining vascular health by dynamically controlling vascular tone (36) through the release of several vasoactive substances, including nitric oxide, prostacyclin, and endothelin-1 (ET-1) (31). Endothelial dysfunction is characterized by an endothelium that facilitates inflammation, thrombosis, vasoconstriction, and atherosclerotic lesion formation $(18,64,81)$. Thus, endothelial dysfunction precedes the development of atherosclerosis $(64,80)$, and contributes to the development of CVD $(18,81)$. Endothelial dysfunction is evident in the microvasculature, which reflects systemic vascular dysfunction and can therefore be used as a marker of CVD risk $(11,45,50)$. Microvascular dysfunction is apparent in the cutaneous microcirculation $(2,39)$ and can be studied with minimally invasive procedures, making it a useful model for studying the mechanisms of vascular diseases (32).

ET-1 is a powerful vasoconstrictor, can contribute to endothelial dysfunction, and has been implicated in the development of atherosclerosis $(5,19,38)$. ET-1 is secreted abluminally by endothelial cells and binds to two G-protein-coupled receptor subtypes, ET-A and ET-B $(35,82)$. In the vasculature, both ET-A and ET-B receptors are located on vascular smooth muscle cells (VSMCs) and mediate vasoconstriction, while ET-B receptors are also located on the endothelium and mediate vasodilation (21). Notably, ovarian hormones affect plasma ET-1 concentration and may contribute to functional differences in the regulation of vascular tone by the endothelin system. Plasma ET-1 is higher in men than in women, and even lower in pregnant women (62), showing an inverse relationship with estrogen and progesterone (P4) levels. Additionally, during the menstrual cycle, ET-1 is the highest during the menstrual 
phase when estrogen and P4 are at their lowest (63). Furthermore, compared to men, women have a higher proportion of ET-B receptors and a greater binding affinity for ET-B compared to ET-A receptors (21). Kellogg et al. demonstrated that ET-B receptors in the cutaneous microcirculation mediate vasodilation in young women, but mediate vasoconstriction in young men (43). However, hormonal contraceptives or phase of the menstrual cycle was not controlled for in the aforementioned study (43), so the direct impact of ovarian hormones in modulating ET-1 receptor responses remains unclear.

Although evidence suggests ovarian hormones modulate plasma ET-1, it is not known if fluctuations in ovarian hormones throughout the menstrual cycle impact ET1 receptor control of microvascular function. Additionally, the independent effect of $17 \beta$-estradiol (E2) on ET-B receptor expression is unknown. Therefore, the overall goal of this study was to understand the impact of ovarian hormones on ET-B receptors in vivo and in vitro. The central hypothesis was that ovarian hormones mediate microvascular vasodilation through an ET-B receptor mechanism. More specifically we expected that E2 up-regulates ET-B receptor expression on endothelial cells. We tested our central hypothesis through the following aims:

Specific Aim 1 examined ET-B receptor control of microvascular function during the menstrual cycle. We used the skin as a model of microvascular function and measured skin blood flow (SkBF) responses during microdialysis perfusions of an ET$\mathrm{B}$ receptor antagonist (BQ-788) during two phases of the menstrual cycle, early follicular (EF) and mid-luteal (ML). We hypothesized that ET-B receptors would mediate vasodilation when E2 and P4 are elevated (ML phase), and that ET-B receptors would mediate vasoconstriction when E2 and P4 are depressed (EF phase). 
Specific Aim 2 directly examined the effect of E2 on ET-B receptor expression on endothelial cells. Human umbilical vein endothelial cells (HUVECs) were treated with 5 escalating doses of E2 and ET-B receptor expression was quantified using Western Blots. We hypothesized that ET-B receptor expression on HUVECs would be up-regulated as E2 dose increased.

To our knowledge, this is the first study to examine ET-B receptor expression in HUVECs in response to E2, as well as examine ET-B receptor control of microvascular function across the menstrual cycle. ET-B receptors, which can mediate either vasodilation or vasoconstriction, are an important regulator of vascular function. Therefore, understanding their regulation in response to changes in ovarian hormones is important, particularly as women age and go through menopause. 


\section{Chapter 2}

\section{INTRODUCTION}

Cardiovascular disease (CVD) is the leading cause of death in women, with more than 400,000 women dying from CVD in 2010 (54). In addition to increased mortality, CVD affects more women than men, particularly after the fourth decade of life (40). Changes to the normal functioning of blood vessels, particularly in endothelial cells, play a large role in the development of CVD (76). Endothelial dysfunction has been shown to precede the development of atherosclerosis $(61,75)$ and contribute to the development of CVD $(17,76)$. Endothelial dysfunction has been associated with imbalances in endothelium-derived vasoactive substances, such as nitric oxide (NO) and endothelin-1 (ET-1).

Changes in ET-1 regulation and function may contribute to endothelial dysfunction and the increased prevalence of CVD among women. ET-1 can bind to two different receptors: endothelin receptor A (ET-A) and endothelin receptor B (ETB). In the vasculature, ET-A receptors are located on the smooth muscle, while ET-B receptors are found on both endothelial cells and VSMCs (21). When ET-1 binds to either receptor on VSMCs, it mediates vasoconstriction and cell proliferation, while ET-B receptors on the endothelium facilitate vasodilation through the stimulation of endothelial NO synthase $(21,43,44)$.

Importantly, ovarian hormones have been shown to modulate ET-1 concentration and may contribute to functional differences between men and women in the regulation of vascular tone. For example, plasma ET-1 is higher in men 
compared to women, which may be mediated by sex hormones (62). Additionally, women have a higher proportion of ET-B receptors compared to men (21), which mediate vasodilation in young women compared to vasoconstriction in young men (43). ET-B receptors appear to function differently in older women, however, demonstrating a greater vasoconstrictor tone in post-menopausal women (73). While these findings suggest that there is a difference in ET-B receptor function with age, it is unclear if this is a direct impact of declining ovarian hormones that occurs after menopause. Importantly, previous studies in young women have not taken into account phase of the menstrual cycle, so it is unclear if ovarian hormones are mediating these aforementioned differences. Therefore, the role of fluctuating ovarian hormones on ET-B regulation of vascular function in women is currently unknown.

Studies in animal and cell models further indicate that ovarian hormones, specifically $17 \beta$-estradiol (E2), modulate ET-1 and its receptors. E2 significantly lowers ET-1 concentration, mRNA expression, and release from human umbilical vein endothelial cells (HUVECs) $(6,41)$. E2 treatment up-regulates the expression of ET-B receptors in the coronary arteries of hyperlipidemic rabbits (60), while downregulating ET-B receptors expression on the smooth muscle cells of the ventricular myocardium of rats (58). Altogether, these studies indicate that E2 modulates the expression of the ET-B receptor, down-regulating its expression in myocardial cells, while up-regulating its expression in coronary arteries, which contain both smooth muscle and endothelial cells. However, the independent effect of E2 on ET-B receptor expression in endothelial cells alone has not been investigated.

The cutaneous circulation has been used as an accessible and representative vascular bed to examine the mechanisms of microvascular function $(2,39,74)$. 
Additionally, laser Doppler flowmetry (LDF) in combination with intradermal microdialysis is beneficial for studying the cutaneous circulation because it allows for the measurement of skin blood flow while simultaneously administering pharmacological substances to garner insight into the specific mechanisms underlying endothelial function and dysfunction. Microvascular dysfunction is apparent in the cutaneous microcirculation $(2,39)$ and can be studied with minimally invasive procedures, making the skin a useful model for studying the mechanisms of vascular diseases (33).

In the present study, we used LDF to measure changes in skin blood flow (SkBF), coupled with cutaneous microdialysis perfusions of endothelin receptor blockers in order to examine how ET-B receptors affect peripheral microvascular function in women during the early follicular (low hormone) and mid-luteal (high hormone) phases of the menstrual cycle. We hypothesized that ET-B receptors would mediate vasodilation when E2 and P4 are elevated (ML phase), and that ET-B receptors would mediate vasoconstriction when E2 and P4 are depressed (EF phase). Additionally, to our knowledge, the direct effect of E2 on ET-B receptor expression in human endothelial cells is currently unknown. Therefore, we used Western blot analyses to measure ET-B receptor expression in HUVECs after 24-hours of E2 treatment. We hypothesized that ET-B receptor expression on HUVECs would be upregulated as E2 dose increased. 


\section{Chapter 3}

\section{METHODS}

\subsection{Introduction}

The purpose of Aim 1 was to examine ET-B receptor control of microvascular function during the menstrual cycle. While the literature demonstrates that there are sex differences regarding the endothelin system and suggest that these differences may be attributed to ovarian hormones, the direct impact of cycling ovarian hormones on ET-B receptor function is currently unknown. Understanding how these receptors act under the influence of E2 and P4 is important, since ET-B receptors on endothelial cells mediate vasodilation, a cardioprotective mechanism. Therefore, although it is important to understand what happens with aging and menopause, an essential first step is to directly assess the impact of normal hormonal fluctuations in young women on the endothelin system.

The purpose of Aim 2 was to directly examine the effect of E2 on ET-B receptor expression on endothelial cells. The literature proposes that E2 directly affects ET-1 production and secretion from endothelial cells, with studies reporting that female HUVECs incubated with E2-rich medium produce and secrete less ET-1 than those in E2-deprived medium $(6,41)$. Additionally, animal studies have suggested that E2 up-regulates ET-B receptor expression on endothelial cells $(58,60)$, but to our knowledge there has not been a study looking at the effects of E2 on ET-B receptor expression or regulation in human endothelial cells. Therefore, in addition to Aim 1, understanding how E2 directly affects ET-B receptors on human endothelial 
cells is important for further understanding the cardioprotective mechanisms that young women seem to exhibit. It is necessary to understand if this mechanism is the result of E2 or some other ovarian hormone, and this study will add to that understanding.

\subsection{Participants}

Eight women between the ages of 18-30 years were recruited for this study. All participants were non-smoking, with a BMI $<30 \mathrm{~kg} / \mathrm{m}^{2}$, free from any known CVD, and had regular menstrual cycles ( 1 cycle every 28 days). Participants were excluded if they took oral contraceptives, which have been shown to affect endogenous E2, a hormone of interest in this study (71). Women were excluded from this study if they were pregnant (determined by urine pregnancy test), were planning to become pregnant, or were breast-feeding. Additional exclusion criteria included cancer, kidney or liver disease, neurological disease, high cholesterol, history of blood clots, heart disease, high blood pressure, stroke, or any other chronic disease. Furthermore, women with abnormal vaginal bleeding not related to their period, those with fibroids in their uterus, or those with irregular cycles were also excluded. Experiments were approved by the Institutional Review Board at the University of Delaware and conformed to the guidelines set forth by the Declaration of Helsinki. All participants gave verbal and written consent prior to study participation.

\subsection{Screening Visit: Nurse Managed Health Center at the University of Delaware}

Participants were screened by the Nurse Managed Health Center (NMHC) at the University of Delaware prior to participating in the study. Before this visit, all women filled out a complete medical history form and answered a menstrual history 
questionnaire. Women reported to the NMHC in the morning after an overnight fast, where height, weight, resting blood pressure and a resting electrocardiogram were measured. Based on the recommendation from the American Heart Association, resting blood pressures were performed in triplicate and averaged together (61). A blood sample was taken to assess the participant's liver and kidney function, cholesterol, glucose, hemoglobin, hematocrit, and electrolytes.

\subsection{Experimental Visits: Vascular Physiology Laboratory at the University of Delaware}

Subjects participated in two experimental visits during two different phases of the menstrual cycle. Consistent with previous studies, the mid-luteal phase visit occurred during days 20-25 of the menstrual cycle and the early follicular phase visit occurred during days 1-5 of the menstrual cycle $(13,26,47,55)$. Participants refrained from exercise for 24 hours, alcohol and caffeine for 12 hours, and food for at least 4 hours prior to testing. Upon arrival, subjects provided a small urine sample for a pregnancy test and were weighed. After lying supine, a small blood sample was taken to assess serum concentrations of $17 \beta$-estradiol and progesterone, which were used to confirm menstrual cycle phase. Women were instrumented for measures of blood pressure (Dinamap DASH 2000, GE Medical) and intradermal microdialysis (Specific Aim 1; see below).

\subsection{Microvascular Function Assessment}

The cutaneous circulation was used a model of microvascular function for Aim 1 , as it is less invasive than other techniques and has been correlated with CVD risk and endothelial dysfunction $(2,33)$. Three microdialysis (MD) fibers (CMA 31 Linear, Harvard Apparatus, Holliston, MA) were inserted intradermally on the dorsal side of 
the right forearm as previously described $(20,30,84)$. Under sterile conditions, ice was applied for 10 minutes to the skin surface in order to provide a short-term local anesthetic, without affecting the skin blood flow (SkBF) response (32). Then, a 23gauge needle, which was used as a guide cannula, was inserted underneath the dermis. The entry and exit points of each needle were at least $2 \mathrm{~cm}$ apart, with individual sites separated by at least $2 \mathrm{~cm}$. After insertion of all three needles, microdialysis fibers were threaded through the lumen of the needle and the needles were removed, leaving only the semi-permeable portion of the fiber under the dermis, at a depth of approximately 2-5 $\mathrm{mm}$. After the fibers were in place, they were taped down and connected to a syringe pump (Bioanalytical Systems, West Lafayette, IN). Then, for 60-90 minutes, each site was perfused with lactated Ringers solution (B Braun Medical, Bethlehem, PA) at a rate of $2 \mu \mathrm{l} / \mathrm{min}$. This recovery period after the fiber insertion was necessary to allow local SkBF to return to baseline before measurements could be taken (3). SkBF was measured using laser Doppler flowmetry (LDF) as previously described $(20,30,84)$. SkBF was measured as cutaneous red blood cell flux from $1.5 \mathrm{~mm}^{2}$ of skin with a multi-fiber LDF probe (Moor Instruments, Devon, UK) placed in a local heater, which was placed on the skin directly above each microdialysis site and secured with tape.

\subsection{Experimental Protocol}

After the 60-90 minute recovery period and once SkBF had returned to normal, we collected baseline data for 5-10 minutes. We then turned on the local heaters, which were set to $32^{\circ} \mathrm{C}$, which is similar to normal skin temperature, for 5-10 minutes. After these baseline measurements, there was a 45-minute ET-1 block. Two of the three syringes were randomly replaced with either an ET-B receptor antagonist (BQ- 
788, 300nM, Sigma-Aldrich, St. Louis, MO) or an ET-A receptor antagonist (BQ-123, 500nM, Sigma-Aldrich, St. Louis, MO), while the third site was left with lactated Ringers solution to serve as the control site. The sites were perfused at a rate of 5 $\mu 1 /$ min. After 45 minutes of ET-1 receptor blocker perfusion, the local heaters were set to $42^{\circ} \mathrm{C}$ for approximately $30-40$ minutes, or until there was a stable plateau in SkBF, which is largely NO mediated $(43,54)$. Finally, we replaced all three syringes with sodium nitroprusside (SNP, 28mM, Marathon Pharmaceuticals, Northbrook, IL), perfusing the fibers at a rate of $5 \mu \mathrm{l} / \mathrm{min}$ for approximately 20 minutes with local heaters set to $43^{\circ} \mathrm{C}$, in order to elicit maximal vasodilation. A schematic of the experimental protocol can be seen in Figure 3.1.

\begin{tabular}{|c|c|c|c|c|c|}
\hline Site 1 & Ringers & Ringers & Ringers & Ringers & $\begin{array}{c}\text { SNP } \\
(28 \mathrm{mM})\end{array}$ \\
\hline Site 2 & Ringers & Ringers & $\begin{array}{c}\text { BQ-788 } \\
(300 \mathrm{nM})\end{array}$ & $\begin{array}{c}\text { BQ-788 } \\
(300 \mathrm{nM})\end{array}$ & $\begin{array}{c}\text { SNP } \\
(28 \mathrm{mM})\end{array}$ \\
\hline Site 3 & Ringers & Ringers & $\begin{array}{c}\mathrm{BQ}-123 \\
(500 \mathrm{nM})\end{array}$ & $\begin{array}{c}\mathrm{BQ}-123 \\
(500 \mathrm{nM})\end{array}$ & $\begin{array}{c}\mathrm{SNP} \\
(28 \mathrm{mM})\end{array}$ \\
\hline Protocol & No heating & $\begin{array}{c}\text { Local heat to } \\
32^{\circ} \mathrm{C}\end{array}$ & $\begin{array}{c}\text { Local heat at } \\
32^{\circ} \mathrm{C}\end{array}$ & $\begin{array}{c}\text { Local heat to } \\
42^{\circ} \mathrm{C}\end{array}$ & $\begin{array}{c}\text { Local heat to } \\
43^{\circ} \mathrm{C}\end{array}$ \\
$60-90$ & $5-10$ minutes & 45 minutes & $\sim 45$ minutes & $\sim 20$ minutes \\
\hline
\end{tabular}

Figure 3.1: Schematic of Microvascular Function Assessment Protocol.

\subsection{Data Analysis}

LDF data was recorded at $1000 \mathrm{~Hz}$, using PowerLab (ADInstruments, Bella Vista, New South Wales, Australia). Cutaneous vascular conductance (CVC) was calculated by dividing $\mathrm{SkBF} /$ mean arterial pressure (MAP). We analyzed a 5-minute segment after a plateau was reached during local heating to $42^{\circ} \mathrm{C}$ and a 2 -minute 
segment during the SNP + local heating to $43^{\circ} \mathrm{C}$ (maximum dilation). $\mathrm{CVC}$ for each individual site during the plateau was expressed as a percent of maximum dilation to account for site-to-site variations in SkBF and was used as an indicator of dynamic microvascular function.

\subsection{Blood Analyses}

Venous blood samples that were analyzed for ovarian hormones were collected in plain red-top blood tubes (4ml, BD Vacutainer, Franklin Lakes, NJ). Plasma E2 and P4 levels were measured using competitive enzyme-linked immunosorbent assays (ELISA) (Alpco, Salem, NH). The range for the E2 assay was $20-3200 \mathrm{pg} / \mathrm{ml}$ with a sensitivity of $10 \mathrm{pg} / \mathrm{ml}$. Intra-assay and interassay coefficients of variation for the E2 assay were $3.52 \%$ and $1.42 \%$, respectively. The range for the ultra-sensitive E2 assay was $0-200 \mathrm{pg} / \mathrm{ml}$ with a sensitivity of $1.399 \mathrm{pg} / \mathrm{ml}$. Intra-assay and interassay coefficients of variation for the ultra-sensitive E2 assay were $2.72 \%$ and $0.17 \%$, respectively. The range for the $\mathrm{P} 4$ assay was $0.3-60 \mathrm{ng} / \mathrm{ml}$ with a sensitivity of 0.1 $\mathrm{ng} / \mathrm{ml}$. Intra-assay and interassay coefficients of variation for the P4 assay were $3.52 \%$ and $1.42 \%$, respectively. All samples were measured at a wavelength of $450 \mathrm{~nm}$ on an Infinite F200 Pro microplate reader and data was analyzed with Magellan IQ software (Tecan Group Ltd., Männedorf, CH).

\subsection{Materials for Cell Culture}

All culture media, media supplements, and human umbilical vein endothelial cells (HUVECs), which have been isolated from a female single-donor umbilical vein, were purchased from Lonza Clonetics (Walkersville, MD). 17 $\beta$-estradiol (E2) was purchased from Sigma-Aldrich (St. Louis, MO). Antibodies to the endothelin-1 
receptor B (ET-B) were purchased from Santa Cruz Biotechnology (Dallas, TX). RIPA Buffer and the phosphatase-protease inhibitor cocktail were purchased from Thermo Fisher Scientific (Hampton, NH).

\subsection{Cell Culture and Estrogen Treatment}

HUVECs were cultured and serially passaged on uncoated flasks containing endothelial basal medium-2 (EBM-2). The media was supplemented with endothelial growth medium-2 (EGM-2), which contained 2\% fetal bovine serum (FBS), 0.04\% hydrocortisone, $0.4 \%$ human fibroblast growth factor basic, $0.1 \%$ human vascular endothelial growth factor (hVEGF), 0.1\% human insulin-like growth factor-1 (IGF-1), $0.1 \%$ ascorbic acid, $0.1 \%$ human epidermal growth factor (hEGF), $0.1 \%$ GA-1000, and $0.1 \%$ heparin. HUVECs at passage 5 were transferred to T-25 flasks and were grown until they reached at least $80 \%$ confluence. They were identified as endothelial cells by their characteristic cobblestone appearance (15). HUVECs were placed in hormone-free medium, which contained phenol red-free medium 199, supplemented with $20 \%$ charcoal/dextran-treated FBS, EGM-2, pyruvic acid, and antibiotics, for 48 hours prior to estradiol treatments to avoid any estrogenic activity (10).

HUVECs were then treated with E2 over the following range of concentrations: $0,0.1,0.5,1,5,10,50$, and $100 \mathrm{ng} / \mathrm{ml}$ for 24 hours. These concentrations were chosen based on a study from Caulin-Glaser et al., which demonstrated a dose-response relationship between E2 treatment and NO release (15). All treatments were added in hormone free medium and experiments were performed at $80-90 \%$ confluence. After a 24-hour incubation with E2, the cells were lifted off of the dishes with trypsin (3-5 min). It was verified that the cells had lifted off of the dishes by checking to make sure they were free-floating under an inverted microscope. 
Cells were spun down at $500 \mathrm{rpm}$ for $5 \mathrm{~min}$ and then resuspended in $0.5 \mathrm{~mL}$ sterile media.

\subsection{Determination of ET-B Receptor Expression}

ET-B receptor expression was determined through Western blots (see Appendix B). Cells were lysed with RIPA buffer (25mM Tris-HCl (pH 7.6), 150mM $\mathrm{NaCl}, 1 \% \mathrm{NP}-40,1 \%$ sodium deoxycholate, $0.1 \% \mathrm{SDS}$ ) containing $0.01 \%$ proteasephosphatase inhibitor cocktail and 0.01\% EDTA. Lysates were centrifuged at 10,000 g $\left(4^{\circ} \mathrm{C}, 10 \mathrm{~min}\right)$. Protein concentration in the supernatants was determined through a BCA (bicinchoninic acid) protein assay (Thermo Fisher Scientific, Hampton, NH). Consistent with previous studies $(23,48)$, samples were heated for $5 \mathrm{~min}$ at $90^{\circ} \mathrm{C}$. Then, $10 \mu \mathrm{g}$ of protein was separated by electrophoresis $(100 \mathrm{~V} / \mathrm{gel}$ for $60 \mathrm{~min})$ on $10 \%$ sodium dodecyl sulfate-polyacrylamide gels and transferred onto polyvinylidene difluoride (PVDF) membranes (50V/gel for 60min). Membranes were blocked with SuperBlock for either 1 hour at room temperature or overnight at $4{ }^{\circ} \mathrm{C}$. Samples were then incubated either overnight at $4{ }^{\circ} \mathrm{C}$ or for 1 hour at room temperature with anti-ETB goat polyclonal IgG antibody (N-21; 1:200; Santa Cruz Biotechnology) followed by incubation with the secondary antibody (donkey anti-goat IgG-HRP antibody; 1:2000; Santa Cruz Biotechnology) for 1 hour at room temperature. Membranes were stained with WesternSure ECL detection reagents (LI-COR, Lincoln, NE) and digitized and analyzed using the C-DiGit Chemiluminescent Western Blot Scanner system (LICOR). Protein abundance was expressed as relative units normalized to $\beta$-actin bands (anti- $\beta$-actin rabbit polyclonal IgG; 1:1000; Santa Cruz Biotechnology). 


\subsection{Sample Size and Power Estimations}

Sample size and power calculations were based on a study by Kellogg et al., which reported differences in percent change in CVC during microdialysis coupled with LDF (43). They found differences of $19 \pm 3 \%$ for men and $10 \pm 1 \%$ for women when comparing sites perfused with BQ-788 (ET-B receptor antagonist) and those perfused with Ringers solution (control) (43). Therefore, with a total of 8 women and $\alpha<0.05$, this effect size would provide $>80 \%$ power to show significant differences (GPower 3.1, Düsseldorf, DE).

\subsection{Statistical Analyses}

The main variable of interest for Aim 1 was the vasodilatory response to local heating in the ET-B receptor-blocked site (BQ-788) compared to the control site (Ringers) during the EF and ML phases of the menstrual cycle; therefore comparisons were made within groups using a Student's paired t-test. Comparisons were also made using Student's paired t-tests between the ET-A receptor-blocked site (BQ-123) and the control site during both phases of the menstrual cycle, which served as our control. Furthermore, comparisons were made between the control sites from one phase to the next to assess any differences in vasodilatory capacity of the skin across the menstrual cycle. For Aim 2, the main variable of interest was ET-B receptor expression in the HUVECs across a variety of doses of E2. Each dose response was performed at least three times, with each data point performed in duplicate. An ANOVA was performed to make comparisons between doses. Significance for all data was set at $\alpha<0.05$. Results are expressed as mean $\pm \mathrm{SE}$. 


\section{Chapter 4}

\section{RESULTS}

\subsection{Subject Characteristics}

Eight subjects completed the experimental protocol. All subjects were healthy, young women, who were free from any chronic disease. They were not taking oral contraceptives and did not use tobacco products. Out of the group of subjects, two were Asian, three were Black, four were Caucasian, and one was Asian Pacific American (some subjects identified as being more than one race). Subjects ranged from 19-22 years, with an average of $20.4 \pm 0.3$ years. All subjects maintained a healthy weight (average body mass index (BMI) was $23.8 \pm 1.1 \mathrm{~kg} / \mathrm{m}^{2}$ ) and were normotensive (average systolic blood pressure (SBP) was $114 \pm 2 \mathrm{mmHg}$, average diastolic blood pressure (DBP) was $70 \pm 3 \mathrm{mmHg}$, and average mean arterial pressure (MAP) was $85 \pm 2 \mathrm{mmHg}$ ). Resting heart rate (HR) was $58 \pm 4$ beats per minute (bpm). Complete subject characteristics from the screening visit are in Table 4.1.

All subjects completed both study visits, where their estradiol and progesterone were measured. Each subject was verified to be within the early follicular phase (EF) or the mid-luteal phase (ML) for visits 1 and 2, respectively. Average estradiol concentration and progesterone concentration were significantly higher during the mid-luteal visit compared to the early follicular visit (Table 4.2). FMD values were not significantly different between visits (EF: $8 \pm 1 \%$ change versus $6 \pm 1 \%$ change; $p=$ 0.3529). Full subject characteristics from the two experimental visits are in Table 4.2. 
Table 4.1: Subject Screening Characteristics.

\begin{tabular}{|c|c|c|}
\hline \multirow{2}{*}{$\begin{array}{l}\text { Variable } \\
\text { Demographic Information }\end{array}$} & \multicolumn{2}{|c|}{$n=8$} \\
\hline & & \\
\hline & 20.4 & \pm 0.3 \\
\hline Height (cm) & 164.8 & \pm 2.0 \\
\hline Weight (kg) & 64.7 & $\pm \quad 3.7$ \\
\hline $\mathrm{BMI}\left(\mathrm{kg} / \mathrm{m}^{2}\right)$ & 23.8 & $\pm \quad 1.1$ \\
\hline Cycle Length (days) & 30 & \pm 1 \\
\hline \multicolumn{3}{|l|}{ Hemodynamic Measurements } \\
\hline Heart rate (beats/min) & 58 & \pm 4 \\
\hline $\mathrm{SBP}(\mathrm{mmHg})$ & 114 & \pm 2 \\
\hline $\mathrm{DBP}(\mathrm{mmHg})$ & 70 & \pm 3 \\
\hline MAP (mmHg) & 85 & \pm 2 \\
\hline \multicolumn{3}{|l|}{ Renal Function } \\
\hline Blood urea nitrogen (mg/dl) & 11.7 & $\pm \quad 1.1$ \\
\hline Serum creatinine $(\mathrm{mg} / \mathrm{dl})$ & 0.8 & \pm 0.03 \\
\hline $\mathrm{eGFR}\left(\mathrm{ml} \times \min ^{-1} \times 1.73 \mathrm{~m}^{-2}\right)$ & 110.4 & \pm 5.1 \\
\hline \multicolumn{3}{|l|}{ Blood Chemistry } \\
\hline Total cholesterol (mg/dl) & 151.4 & \pm 8.6 \\
\hline High-density lipoprotein (mg/dl) & 68.1 & $\pm \quad 5.1$ \\
\hline Low-density lipoprotein (mg/dl) & 69.9 & \pm 8.6 \\
\hline Triglycerides (mg/dl) & 67.0 & \pm 11.8 \\
\hline Hemoglobin (mg/dl) & 12.8 & \pm 0.3 \\
\hline Hematocrit $(\%)$ & 39.4 & $\pm \quad 0.9$ \\
\hline Glucose (mg/dl) & 74.4 & $\pm \quad 1.7$ \\
\hline Sodium $(\mathrm{mmol} / \mathrm{L})$ & 138.4 & $\pm \quad 0.8$ \\
\hline Potassium $(\mathrm{mmol} / \mathrm{L})$ & 4.1 & \pm 0.1 \\
\hline Calcium (mg/dl) & 9.3 & $\pm \quad 0.1$ \\
\hline
\end{tabular}

Body mass index (BMI), diastolic blood pressure (DBP), mean arterial pressure (MAP), and systolic blood pressure (SBP). Data are presented as means $\pm \mathrm{SE}$. 
Table 4.2: Subject Characteristics during Experimental Visits.

\begin{tabular}{|c|c|c|}
\hline Variable & Early Follicular Visit & Mid-Luteal Visit \\
\hline Weight (kg) & $64.4 \pm 3.8$ & $64.4 \pm 3.7$ \\
\hline $\mathrm{SBP}(\mathrm{mmHg})$ & $107 \pm 3$ & $100 \pm 2 *$ \\
\hline DBP (mmHg) & $65 \pm 3$ & $59 \pm 1 *$ \\
\hline MAP (mmHg) & $79 \pm 3$ & $72 \pm 2 *$ \\
\hline Day of Cycle & $4 \pm 0.4$ & $22 \pm 1 *$ \\
\hline Estradiol, serum (pg/ml) & $51.1 \pm 12.5$ & $132.9 \pm 23.1 *$ \\
\hline Progesterone, serum (ng/ml) & $0.9 \pm 0.3$ & $4.8 \pm 1.3^{*}$ \\
\hline
\end{tabular}

Diastolic blood pressure (DBP), mean arterial pressure (MAP), and systolic blood pressure (SBP). Data are presented as means $\pm \mathrm{SE}$.

$*_{p}<0.05$ vs. Early Follicular Visit.

\subsection{Microvascular Responses to ET-1 Receptor Blockade}

There were no differences in \% CVCmax for the control sites (Lactated Ringers) between the early follicular and mid-luteal visits (EF: $87.5 \pm 2.3 \% \mathrm{CVCmax}$ versus ML: $90.0 \pm 2.3 \% \mathrm{CVCmax}, \mathrm{p}>0.05)$, indicating that the dilatory capacity of the skin vasculature was not different between phases of the menstrual cycle. During the mid-luteal phase, \%CVCmax from heating tended to be lower in the ET-B blocked site compared to the control site $(\mathrm{p}=0.07$; Figure 4.1 panel A). Consistent with our hypothesis, this would suggest that the ET-B receptors mediate vasodilation during the mid-luteal phase, when estradiol and progesterone are both elevated. It is interesting to note that seven subjects had a reduction in blood flow in the BQ-788 perfused site, while only one had an increase in blood flow (Figure 4.1 panel B). Contrary to our hypothesis, there were no differences in \% CVCmax during heating between the ET-B blocked site (BQ-788) and the control site during the early follicular phase $(\mathrm{p}>0.05)$. This suggests that ET-B receptors are not playing a large role in cutaneous microvascular vasodilation when estradiol and progesterone levels are low (Figure 4.2). Finally, there were no differences between the ET-A blocked site and the control 
site during the early follicular phase or the mid-luteal phase (Figure 4.3 panels A and B, respectively). Since ET-A receptors are located solely on smooth muscle and therefore only mediate constriction of the vasculature, this would suggest that ET-A receptors are not involved in regulating microvascular vasodilatory responses in these young women and are not largely affected by fluctuating ovarian hormones. Thus, ET$\mathrm{B}$, rather than ET-A receptors, may have the predominate effect on the vasodilatory capacity of the microcirculation in young women, particularly when ovarian hormones are elevated. 

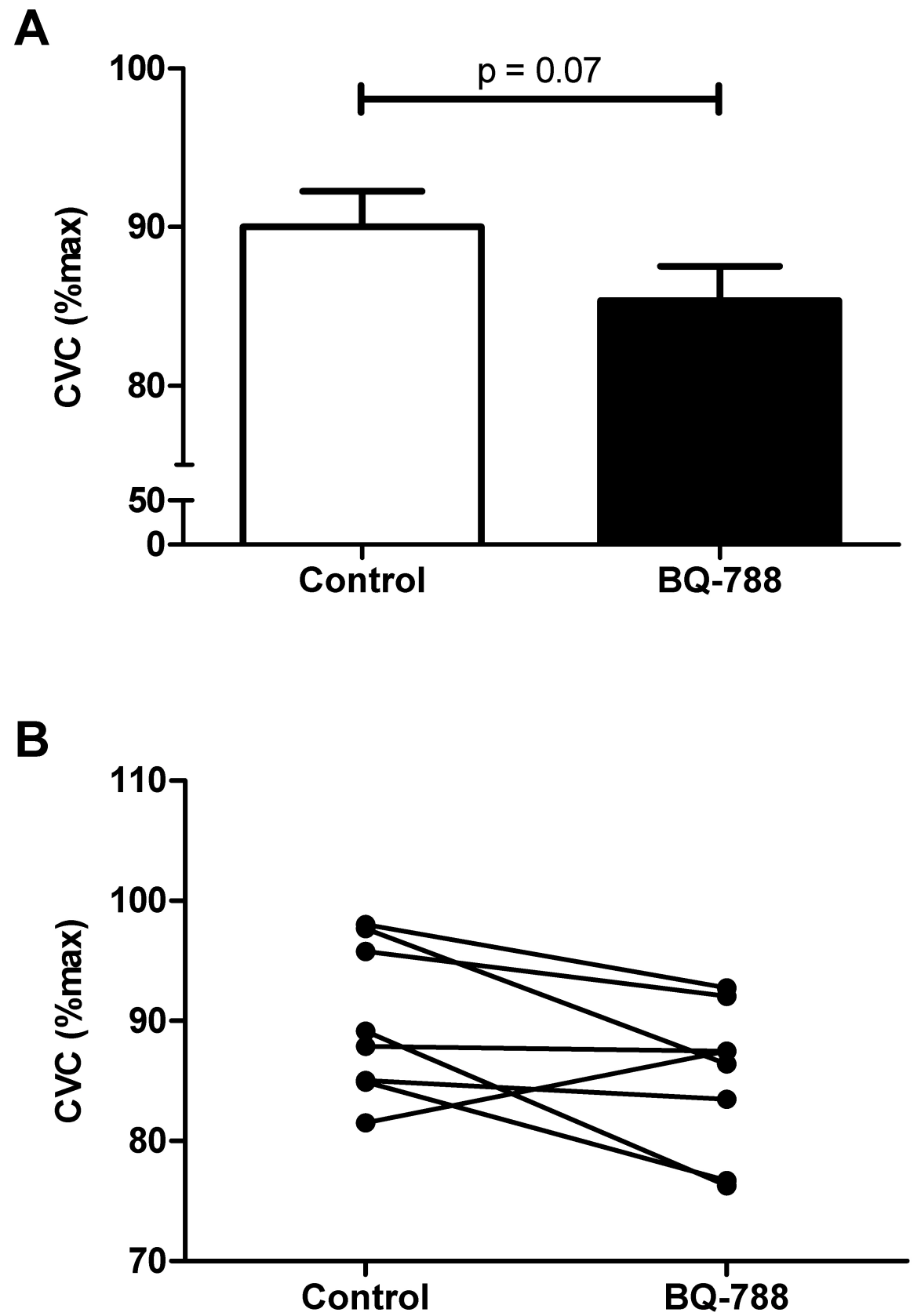

Figure 4.1: Response to ET-B Receptor Blockade during the Mid-Luteal Phase. Cutaneous vascular conductance (\%max) in two MD sites: the control site (perfused with Ringers; open bar) and the ET-B receptor blocked site (perfused with BQ-788; closed bar). Data are presented as means $\pm \mathrm{SE}$ in panel A, while individual data points are presented in panel B. 
A

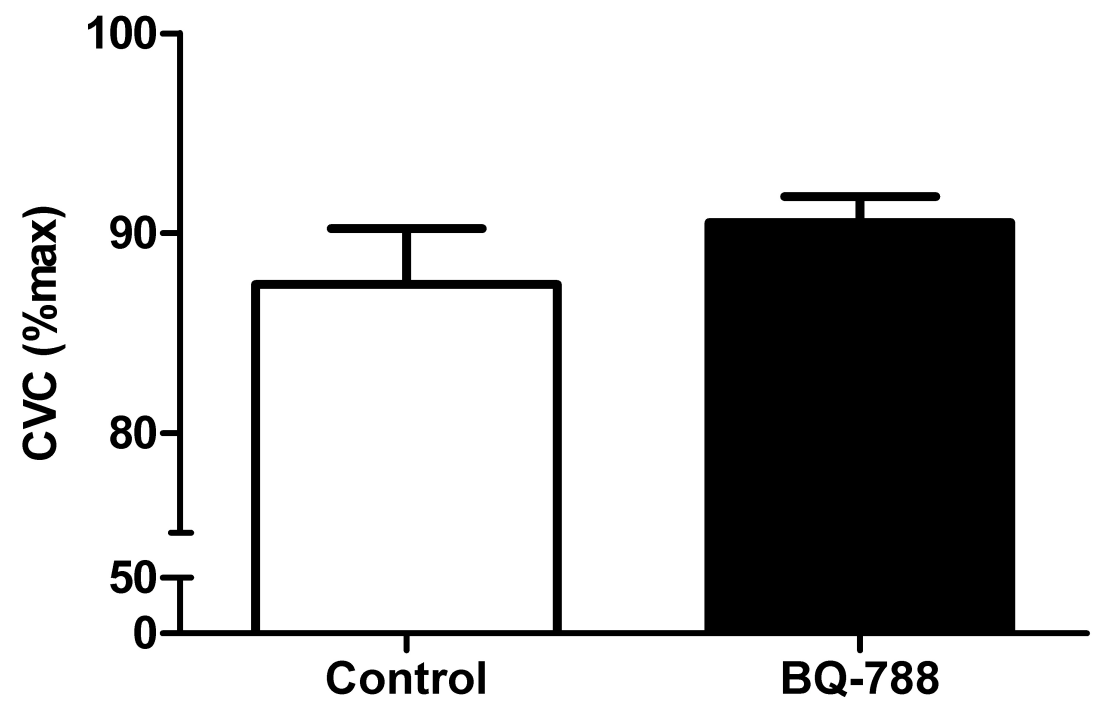

B

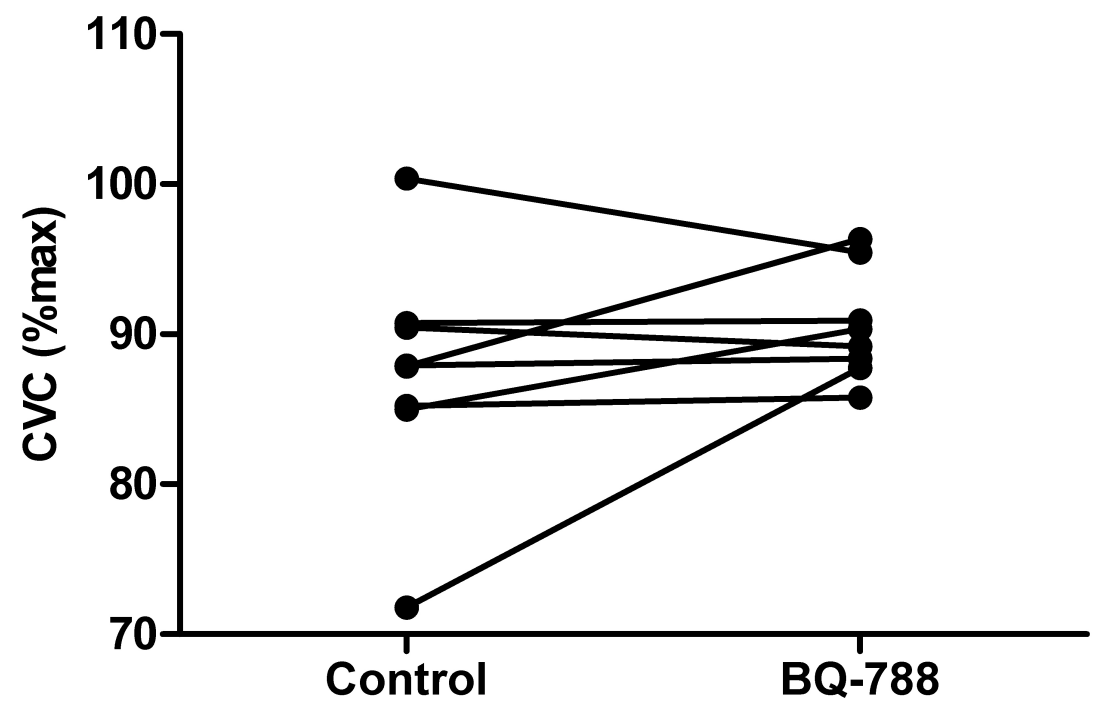

Figure 4.2: Response to ET-B Receptor Blockade during the Early Follicular Phase. Cutaneous vascular conductance (\%) max) in two MD sites: the control site (perfused with Ringers; open bar) and the ET-B receptor blocked site (perfused with BQ-788; closed bar). Data are presented as means $\pm \mathrm{SE}$ in panel $\mathrm{A}$, while individual data points are presented in panel B. 

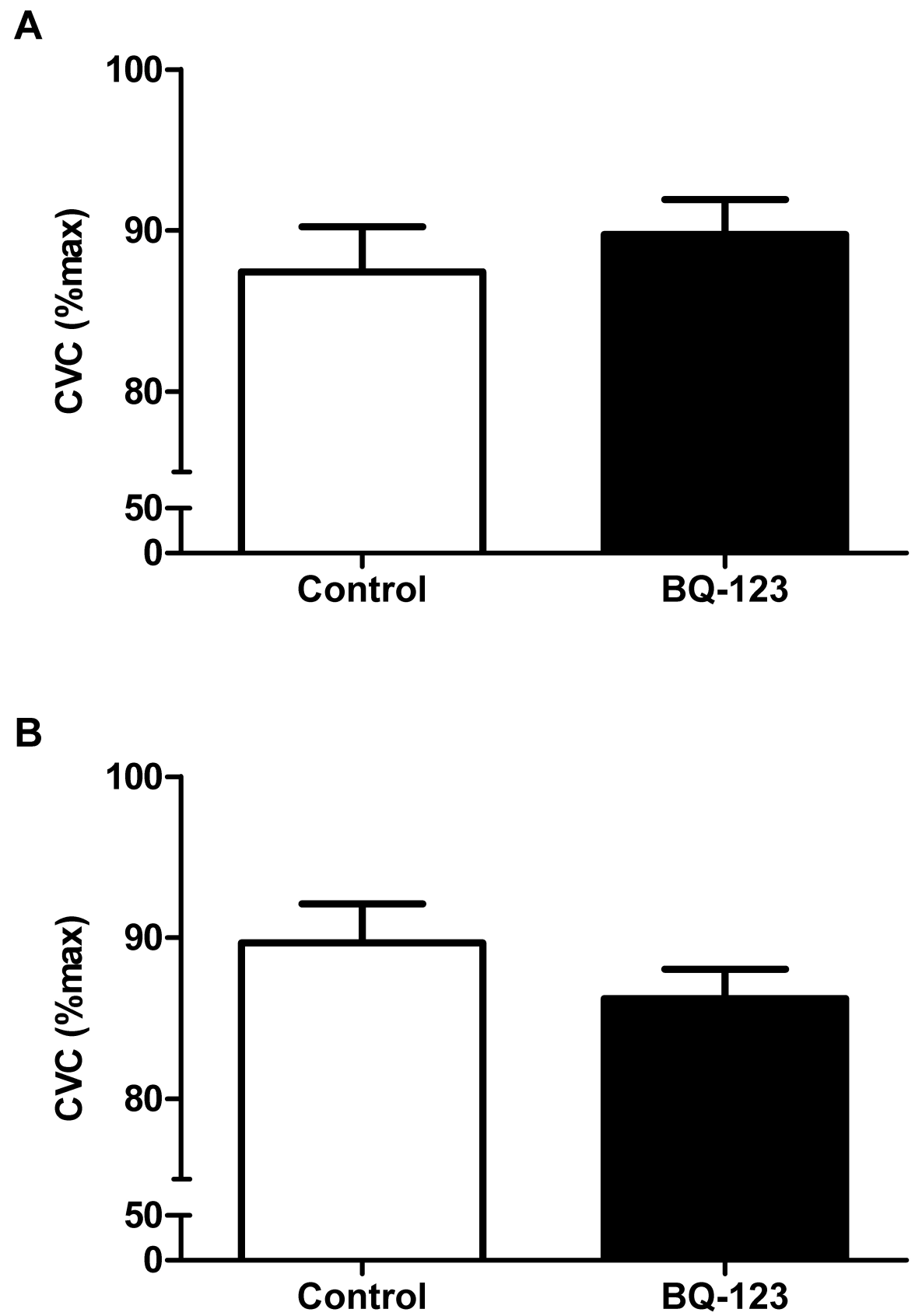

Figure 4.3: Responses to ET-A Receptor Blockade. Cutaneous vascular conductance (\%max) in two MD sites: the control site (perfused with Ringers; open bars) and the ET-A receptor blocked site (perfused with BQ-123; closed bars). Panel A: data from early follicular visit. Panel B; data from the mid-luteal visit. Data are presented as means $\pm \mathrm{SE}$. 


\subsection{Effect of Estradiol on ET-B Receptor Expression}

To determine whether E2 affects ET-B receptor expression on endothelial cells, we examined protein expression of ET-B receptors from three sets of femaleonly HUVECs over the following range of E2 concentrations: $0,0.1,0.5,1,5,10,50$, and $100 \mathrm{ng} / \mathrm{ml}$ for 24 hours.

Protein concentration in the supernatants was determined through a BCA protein assay and there were no differences in protein concentration among the various E2 treatments. Based on these results and previous studies $(23,48), 10 \mu \mathrm{g}$ of protein from each set of samples was loaded into each well. All expression intensity was normalized to the $0.0 \mathrm{ng} / \mathrm{ml} \mathrm{E2-treated} \mathrm{sample} \mathrm{(positive} \mathrm{control)} \mathrm{and} \mathrm{to} \beta$-actin. There were no significant differences in ET-B receptor expression among any of the 24-hour E2 doses $(p=0.7682$; Figure 4.4). 


\section{ET-B Receptor Expression}
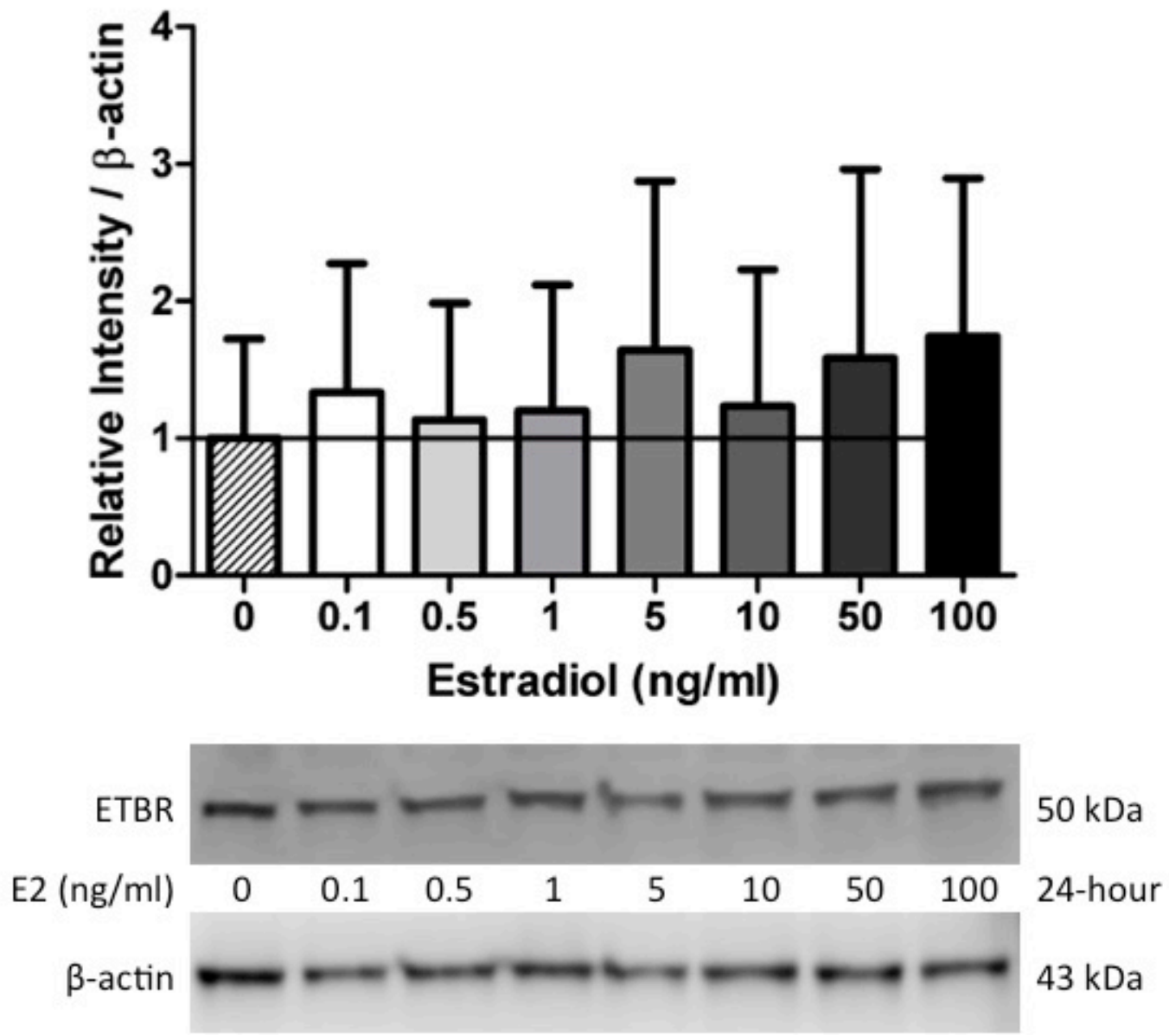

Figure 4.4: ET-B Receptor Expression. ET-B receptor intensity normalized to positive control ( $0 \mathrm{ng} / \mathrm{ml} \mathrm{E2}$; line at 1.0 relative intensity) and then to $\beta$ actin measured by Western blot. Blots from left to right are the following E2 doses: 0, 0.1, 0.5, 1, 5, 10, 50, and $100 \mathrm{ng} / \mathrm{ml}$. Data are presented as means $\pm \mathrm{SE}, \mathrm{p}=0.7682$, and $\mathrm{n}=3$ in each group. 


\section{Chapter 5}

\section{DISCUSSION}

To our knowledge, this is the first study to examine in vivo and in vitro ET-B response to changing ovarian hormone levels (across the menstrual cycle). Our central hypothesis was that ET-B receptors would mediate vasodilation during the mid-luteal phase of the menstrual cycle (when E2 and P4 are elevated) and that this would primarily be mediated by E2. The main findings of the current investigation are that although acute E2 treatment did not alter ET-B receptor expression, our data suggest that chronic fluctuations in ovarian hormones during the menstrual cycle modulate ET-B receptor responses in women. These preliminary findings are an important first step in identifying the interactions among ovarian hormones and ET-1 receptor responses in women.

\subsection{Ovarian Hormones and ET-1 Receptor Function}

Although the importance of ET-1 and its involvement with vascular dysfunction and CVD are well known, less is understood about how ET-1 and its receptors are regulated by sex hormones. Data from previous studies demonstrate differences in ET-1 receptor density and responses between men and women, but the contribution of sex hormones remains to be elucidated. For example, women have a greater proportion of ET-B receptors compared to men (21) and ET-B receptors mediate vasodilation in young women, while mediating vasoconstriction in young men (43). It is important to note that previous studies have not controlled menstrual cycle day when testing young women, so it is unclear how cycling ovarian hormones are affecting the ET-B receptors. Our study extends previous findings by examining ET-1 
receptor responses at two distinct time points of the menstrual cycle; our preliminary findings suggest that ET-B receptors tend to mediate vasodilation during the midluteal phase of the menstrual cycle, when estradiol and progesterone are elevated, compared to the early follicular phase. It is also worthwhile to note that there were no differences in skin blood flow in the control sites between the early follicular and midluteal visits, which would indicate that the vasodilatory capacity of the skin vasculature is not different between phases of the menstrual cycle.

Contrary to our hypothesis, there were no differences in the ET-B blocked site and the control site during the early follicular phase, suggesting that these receptors do not play a large role in cutaneous microvascular vasodilatory responses when circulating estradiol and progesterone are low. This could indicate that ET-B receptors, which have been shown to mediate vasoconstriction in men $(43,73)$ and post-menopausal women (73), are affected by something other than low levels of estradiol and progesterone. However, while E2 and P4 levels are low in the early follicular compared to the mid-luteal phase of the menstrual cycle, these hormones are not as low as what is observed in post-menopausal women. Thus, the presence of chronic fluctuations in ovarian hormones in young cycling women do not result in an ET-B mediated vasoconstriction. It is possible that testosterone may play a role in modulating ET-1 receptor responses. For example, polycystic ovary syndrome (PCOS) is characterized by elevated androgen levels and is associated with metabolic disorders, as well as endothelial dysfunction $(1,28)$. Interestingly, ET-B receptormediated vasodilation is blunted in women with PCOS (84). The hyperandroidism and overall abnormal hormonal profile of women with PCOS is likely playing a key role in this attenuated ET-B vasodilation. While these hormonal changes are important in 
young women with PCOS, they also become important for women as they go through menopause, since women experience both a decline in estradiol and progesterone, as well as a relative increase in testosterone, which may be contributing to endothelial dysfunction linked to ET-B receptor function.

We also found no differences between the ET-A blocked site and the control site during either the early follicular or the mid-luteal phases. Since ET-A receptors are located solely on smooth muscle and therefore only mediate constriction of the vasculature, this would suggest that ET-A receptors do not generally mediate microvascular vasodilatory function in these young women and are not largely affected by fluctuating ovarian hormones. Interestingly, ET-A receptors mediate vasoconstriction in older, post-menopausal women and to an even greater extent in older men (73). Furthermore, studies in women with PCOS show that ET-A receptors also mediate vasoconstriction (84). This could suggest that ET-A receptors are more sensitive to circulating testosterone, as this is higher in men, post-menopausal women, and women with PCOS than in young, pre-menopausal women. Thus, ET-B, rather than ET-A receptors, appear to have the predominate effect on the vasodilatory capacity of the microcirculation, particularly in pre-menopausal women. Taken together, this would suggest that an imbalance between the vasodilatory ET-B receptors and vasoconstrictor ET-A receptors could contribute to vascular dysfunction in women as circulating hormones change throughout the menstrual cycle and over the lifespan.

Finally, several vasoactive substances are involved in regulating vascular function, such as nitric oxide, prostaglandins, angiotensin II, and norepinephrine (37, $56,59)$, all of which are influenced by E2 (78) and interact with ET-1 (66). It is 
possible that the effects we observed in our study are related to the influence of E2 on one or more of these substances; we are not able to determine which redundant mechanisms may be involved from our data. Also, since E2 has been shown to reduce circulating ET-1 $(6,41)$, it is also possible that our findings are related to a reduced production of ET-1. However, vasoconstrictor responses to ET-1, independent of maximum vasoconstrictor capability, do not differ between men and women, despite showing sex differences in ET-A and ET-B responses (73), suggesting that the receptors - and not ET-1 per se - play a crucial role in determining the vascular response. Nevertheless, our data suggest a strong trend indicating that ovarian hormones influence ET-B receptors.

\subsection{ET-B Receptor Responses to Estradiol}

To our knowledge, this is the first study to examine ET-B receptor expression in estradiol-treated human endothelial cells. Although we observed differences in ETB mediated vasodilation in the cutaneous microcirculation across the menstrual cycle, we did not observe differences in ET-B receptor expression in response to acute increasing doses of E2. Previous literature in animal models suggests that E2 affects ET-B receptor expression in myocardial tissue and coronary arteries. Hyperlipidemic rabbits were ovariectomized and then given daily oral treatment of E2, E2 + progestin, progestin alone, or a placebo for 16 weeks (60). The animals were then euthanized and mRNA expression in the coronary arteries was quantified with PCR. It was found that in the E2-only rabbits, ET-B receptor expression was up-regulated in the coronary arteries compared to the placebo animals. Additionally, this expression was completely blunted in the rabbits receiving E2 in combination with a progestin (60). A different study aimed to determine ET-B receptor expression in the ventricular tissue 
of ovariectomized rats and those with an ovariectomy + E2 supplementation, compared to a sham group. As quantified by PCR, ET-B receptor expression in left ventricular tissue was up-regulated after ovariectomy compared to the sham group. Furthermore, this response was completely attenuated in the rats receiving E2 supplementation (58). These data suggest that estrogen down-regulates the expression of ET-B receptors in smooth muscle (ventricular myocardial tissue), while the data from Pedersen et al. (60) suggests that ET-B receptor expression is up-regulated in coronary arteries. Taken together, this would suggest that E2 modulates the expression of the ET-B receptor, down-regulating its expression in smooth muscle cells, while up-regulating its expression in coronary arteries, which contain both smooth muscle and endothelial cells. However, the independent effect of E2 on ET-B receptor expression in endothelial cells alone had not been investigated prior to this study. Therefore, future studies will be done to better ascertain the direct effects of E2 and other hormones on ET-B receptor expression in female endothelial cells.

\subsection{Limitations and Future Directions}

One limitation of this study is the relatively small number of subjects, which may have limited the power to examine estrogen and progesterone's effects on the endothelin system. While our sample size is similar to published studies using similar techniques and populations $(43,84)$, recruiting more young women who were not taking hormonal contraceptives would have been ideal and will be done in future studies. An additional limitation is that we are unable to distinguish which ovarian hormone (estradiol or progesterone) is responsible for contributing to the ET-B mediated vasodilation, since we studied young women during their mid-luteal phase, when both estradiol and progesterone are high. Since data in animal models suggest 
that estradiol is the primary hormone to cause ET-B receptor up-regulation, an alternate study design would be to test the young women during their ovulatory phase, when estradiol is elevated but progesterone is still low. However, testing women during the ovulatory phase requires the use of ovulation prediction kits and can be difficult, since some women menstruate without ovulating (71). The most controlled study method to isolate the individual effects of E2 or P4 is through a hormone suppression-add back model (71). This is achieved through temporary suppression of the menstrual cycle with a gonadotropin-releasing hormone antagonist with a subsequent add-back of the hormone in question (71). This model will be used in future studies in order to see the specific effects of E2 on ET-1 receptor-mediated vasodilation.

Additionally, there were limitations in regard to the estradiol dose response on the endothelial cells. While we loaded $10 \mu \mathrm{g}$ of protein into each well, which is consistent with other studies $(23,48)$, it could be possible that increasing the number of cells and therefore the amount of protein per well could help to show differences in expression. However, given the images from our Western Blot, it appears as if there was sufficient protein. Additionally, the incubation period for the estradiol treatments was only 24 hours. While this was also consistent with previous studies $(10,15)$, it is possible that this was not enough time to allow for integration of functional ET-B receptors into the membrane. Previous studies that have examined ET-B receptors have reported changes in mRNA expression, which can occur over shorter timeframes. Therefore, in future studies, we will both increase the overall treatment duration to examine functional ET-B receptor integration, as well as examine mRNA expression of ET-B receptors. This will add to the current literature, in order to more clearly 
understand how estradiol affects ET-B receptors in human endothelial cells. Ancillary studies will aim to see the effect of progesterone on endothelial cells so that the mechanisms of these sex hormones can be separately understood.

\subsection{Conclusion}

In conclusion, we found that there tended to be a decrease in vasodilation in response to ET-B receptor blockade in young women during the mid-luteal phase. These preliminary data suggest that ET-B receptors tend to mediate vasodilation when circulating estradiol and progesterone levels were high. This extends previous findings that have suggested that ET-B receptors mediate vasodilation in young women, while mediating vasoconstriction in young men (43). Additional research with a larger sample is warranted to more directly understand how circulating ovarian hormones affect ET-B receptor function in vivo, since the literature suggests that these hormones

mediate the sex differences in ET-B receptor function. We also found that there is not an effect of acute E2 treatment on ET-B receptor expression in female endothelial cells. However, since our data suggest that there is a chronic effect of E2 on ET-B receptor function in vivo, future studies are warranted in vitro to ascertain if our functional data is related to an up-regulation of ET-B receptors on endothelial cells. Therefore, future studies will be done to better understand the direct effects of E2 and other hormones on ET-B receptor expression in female endothelial cells.

\subsection{Perspectives}

It is apparent that the endothelin system regulates vascular function differently in men and women, particularly due to the function of the ET-B receptors. Since the endothelin system has been implicated in the pathogenesis of atherosclerosis and 
cardiovascular disease (CVD), and because there are sex differences in the prevalence and mortality of CVD, understanding the mechanisms behind these differences is essential, physiologically and clinically. ET-B receptors located on the endothelium mediate vasodilation and are therefore cardioprotective. Ovarian hormones, both in younger and older women, have been shown to modulate these receptors, which was further confirmed in this study. Additionally, it has been shown that women with PCOS, who have elevated androgens, experience an attenuated ET-B receptormediated vasodilation. This is of particular importance to post-menopausal women, who experience a decline in ovarian hormones. This may lead to a decline in ET-B receptor-mediated vasodilation, which can in turn lead to an overall constrictor tone of the endothelium, and has been connected with endothelial dysfunction and CVD risk. Our data help to further the understanding of how ET-B receptors function within the microvasculature of young women and future studies will demonstrate how estradiol and progesterone separately affect ET-B receptor expression on endothelial cells. This information on the mechanisms contributing to endothelial dysfunction in women may help to develop preventative strategies for women as they age, go through menopause, and lose the cardiovascular protective mechanisms related to circulating ovarian hormones. 


\section{REFERENCES}

1. Abbott DH, Dumesic DA, Franks S. Developmental origin of polycystic ovary syndrome - a hypothesis. J Endocrinol 174: 1: 1-5, 2002.

2. Abularrage CJ, Sidawy AN, Aidinian G, Singh N, Weiswasser JM, Arora S. Evaluation of the microcirculation in vascular disease. $J$ Vasc Surg 42: 3: 574-581, 2005.

3. Anderson TJ, Uehata A, Gerhard MD, Meredith IT, Knab S, Delagrange D, Lieberman EH, Ganz P, Creager MA, Yeung AC. Close relation of endothelial function in the human coronary and peripheral circulations. J Am Coll Cardiol 26: 5: 1235-1241, 1995.

4. Andrew PJ, Mayer B. Enzymatic function of nitric oxide synthases. Cardiovasc Res 43: 3: 521-531, 1999.

5. Best PJ, McKenna CJ, Hasdai D, Holmes DR,Jr, Lerman A. Chronic endothelin receptor antagonism preserves coronary endothelial function in experimental hypercholesterolemia. Circulation 99: 13: 1747-1752, 1999.

6. Bilsel AS, Moini H, Tetik E, Aksungar F, Kaynak B, Ozer A. 17Betaestradiol modulates endothelin-1 expression and release in human endothelial cells. Cardiovasc Res 46: 3: 579-584, 2000.

7. Bonetti PO, Lerman LO, Lerman A. Endothelial dysfunction: a marker of atherosclerotic risk. Arterioscler Thromb Vasc Biol 23: 2: 168-175, 2003.

8. Brain SD, Crossman DC, Buckley TL, Williams TJ. Endothelin-1: demonstration of potent effects on the microcirculation of humans and other species. J Cardiovasc Pharmacol 13 Suppl 5: S147-9; discussion S150, 1989.

9. Bull HA, Bunker CB, Terenghi G, Springall DR, Zhao Y, Polak JM, Dowd PM. Endothelin-1 in human skin: immunolocalization, receptor binding, mRNA expression, and effects on cutaneous microvascular endothelial cells. J Invest Dermatol 97: 4: 618-623, 1991. 
10. Caliceti C, Aquila G, Pannella M, Morelli MB, Fortini C, Pinton P, Bonora M, Hrelia S, Pannuti A, Miele L. 17 $\beta$-estradiol enhances signalling mediated by VEGF-A-delta-like ligand 4-notch1 axis in human endothelial cells. PloS one 8: 8: e71440, 2013.

11. Carberry PA, Shepherd AM, Johnson JM. Resting and maximal forearm skin blood flows are reduced in hypertension. Hypertension 20: 3 : 349-355, 1992.

12. Cardillo C, Kilcoyne CM, Waclawiw M, Cannon RO,3rd, Panza JA. Role of endothelin in the increased vascular tone of patients with essential hypertension. Hypertension 33: 2: 753-758, 1999.

13. Carter JR, Lawrence JE, Klein JC. Menstrual cycle alters sympathetic neural responses to orthostatic stress in young, eumenorrheic women. Am J Physiol Endocrinol Metab 297: 1: E85-91, 2009.

14. Casey DP, Walker BG, Ranadive SM, Taylor JL, Joyner MJ. Contribution of nitric oxide in the contraction-induced rapid vasodilation in young and older adults. J Appl Physiol 115: 4: 446-455, 2013.

15. Caulin-Glaser T, Garcia-Cardena G, Sarrel P, Sessa WC, Bender JR. 17 beta-estradiol regulation of human endothelial cell basal nitric oxide release, independent of cytosolic Ca2+ mobilization. Circ Res 81: 5: 885$892,1997$.

16. Celermajer DS, Sorensen K, Gooch V, Sullivan I, Lloyd J, Deanfield J, Spiegelhalter D. Non-invasive detection of endothelial dysfunction in children and adults at risk of atherosclerosis. The Lancet 340: 8828: 1111$1115,1992$.

17. Clarke JG, Benjamin N, Larkin SW, Webb DJ, Davies GJ, Maseri A. Endothelin is a potent long-lasting vasoconstrictor in men. Am J Physiol 257: 6 Pt 2: H2033-5, 1989.

18. Cohn JN, Quyyumi AA, Hollenberg NK, Jamerson KA. Surrogate markers for cardiovascular disease: functional markers. Circulation 109: 25 Suppl 1: IV31-46, 2004.

19. Donato AJ, Gano LB, Eskurza I, Silver AE, Gates PE, Jablonski K, Seals DR. Vascular endothelial dysfunction with aging: endothelin-1 and endothelial nitric oxide synthase. Am J Physiol Heart Circ Physiol 297: 1: H425-32, 2009. 
20. Dupont JJ, Farquhar WB, Townsend RR, Edwards DG. Ascorbic acid or L-arginine improves cutaneous microvascular function in chronic kidney disease. J Appl Physiol 111: 6: 1561-1567, 2011.

21. Ergul A, Shoemaker K, Puett D, Tackett RL. Gender differences in the expression of endothelin receptors in human saphenous veins in vitro. $J$ Pharmacol Exp Ther 285: 2: 511-517, 1998.

22. Faludi AA, Aldrighi JM, Bertolami MC, Saleh MH, Silva RA, Nakamura Y, Pereira IR, Abdalla DSP, Ramires JAF, Sousa JEM. Progesterone abolishes estrogen and/or atorvastatin endothelium dependent vasodilatory effects. Atherosclerosis 177: 1: 89-96, 2004.

23. Fang W, Wei J, Han D, Chen X, He G, Wu Q, Chu S, Li Y. MC-002 exhibits positive effects against platelets aggregation and endothelial dysfunction through thromboxane A 2 inhibition. Thromb Res 133: 4: 610$615,2014$.

24. Ferrario CM, Strawn WB. Role of the renin-angiotensin-aldosterone system and proinflammatory mediators in cardiovascular disease. $\mathrm{Am} \mathrm{J}$ Cardiol 98: 1: 121-128, 2006.

25. Flammer AJ, Anderson T, Celermajer DS, Creager MA, Deanfield J, Ganz P, Hamburg NM, Luscher TF, Shechter M, Taddei S, Vita JA, Lerman A. The assessment of endothelial function: from research into clinical practice. Circulation 126: 6: 753-767, 2012.

26. Fu Q, Okazaki K, Shibata S, Shook RP, VanGunday TB, Galbreath MM, Reelick MF, Levine BD. Menstrual cycle effects on sympathetic neural responses to upright tilt. J Physiol 587: 9: 2019-2031, 2009.

27. Furchgott RF, Zawadzki JV. The obligatory role of endothelial cells in the relaxation of arterial smooth muscle by acetylcholine. Nature 288: 5789: 373-376, 1980.

28. Gambineri A, Pelusi C, Vicennati V, Pagotto U, Pasquali R. Obesity and the polycystic ovary syndrome. Int J Obes Relat Metab Disord 26: 7: 883-896, 2002.

29. Gerhard M, Walsh BW, Tawakol A, Haley EA, Creager SJ, Seely EW, Ganz P, Creager MA. Estradiol therapy combined with progesterone and endothelium-dependent vasodilation in postmenopausal women. Circulation 98: 12: 1158-1163, 1998. 
30. Greaney JL, DuPont JJ, Lennon-Edwards SL, Sanders PW, Edwards DG, Farquhar WB. Dietary sodium loading impairs microvascular function independent of blood pressure in humans: role of oxidative stress. J Physiol 590: 21: 5519-5528, 2012.

31. Higashi Y, Noma K, Yoshizumi M, Kihara Y. Endothelial function and oxidative stress in cardiovascular diseases. Circ J 73: 3: 411-418, 2009.

32. Hodges GJ, Chiu C, Kosiba WA, Zhao K, Johnson JM. The effect of microdialysis needle trauma on cutaneous vascular responses in humans. $J$ Appl Physiol 106: 4: 1112-1118, 2009.

33. Holowatz LA, Thompson-Torgerson CS, Kenney WL. The human cutaneous circulation as a model of generalized microvascular function. $J$ Appl Physiol 105: 1: 370-372, 2008.

34. Huang PL, Huang Z, Mashimo H, Bloch KD, Moskowitz MA, Bevan JA, Fishman MC. Hypertension in mice lacking the gene for endothelial nitric oxide synthase. 1995.

35. Hynynen MM, Khalil RA. The vascular endothelin system in hypertension--recent patents and discoveries. Recent Pat Cardiovasc Drug Discov 1: 1: 95-108, 2006.

36. Iantorno M, Weiss RG. Using advanced noninvasive imaging techniques to probe the links between regional coronary artery endothelial dysfunction and atherosclerosis. Trends Cardiovasc Med 24: 4: 149-156, 2014.

37. Ignarro LJ, Buga GM, Wood KS, Byrns RE, Chaudhuri G. Endothelium-derived relaxing factor produced and released from artery and vein is nitric oxide. Proc Natl Acad Sci US A 84: 24: 9265-9269, 1987.

38. Ihling C, Szombathy T, Bohrmann B, Brockhaus M, Schaefer HE, Loeffler BM. Coexpression of endothelin-converting enzyme-1 and endothelin-1 in different stages of human atherosclerosis. Circulation 104: 8: 864-869, 2001.

39. Ijzerman R, De Jongh R, Beijk M, Van Weissenbruch M, Delemarrevan de Waal H, Serne E, Stehouwer C. Individuals at increased coronary heart disease risk are characterized by an impaired microvascular function in skin. Eur J Clin Invest 33: 7: 536-542, 2003. 
40. Joyner MJ, Barnes JN, Hart EC, Wallin BG, Charkoudian N. Neural Control of the Circulation: How Sex and Age Differences Interact in Humans. Comprehensive Physiology 2015.

41. Juan SH, Chen JJ, Chen CH, Lin H, Cheng CF, Liu JC, Hsieh MH, Chen YL, Chao HH, Chen TH, Chan P, Cheng TH. 17beta-Estradiol Inhibits Cyclic Strain-Induced Endothelin-1 Gene Expression within Vascular Endothelial Cells. Am J Physiol Heart Circ Physiol 287: 3: H1254-61, 2004.

42. Kellogg DL, Liu Y, Kosiba I, O'Donnell D. Role of nitric oxide in the vascular effects of local warming of the skin in humans. J Appl Physiol 86: 4: 1185-1190, 1999.

43. Kellogg DL, Liu Y, Pergola PE. Selected contribution: Gender differences in the endothelin-B receptor contribution to basal cutaneous vascular tone in humans. $J$ Appl Physiol 91: 5: 2407-11; discussion 238990, 2001.

44. Kohan DE, Rossi NF, Inscho EW, Pollock DM. Regulation of blood pressure and salt homeostasis by endothelin. Physiol Rev 91: 1: 1-77, 2011.

45. Kruger A, Stewart J, Sahityani R, O'Riordan E, Thompson C, Adler S, Garrick R, Vallance P, Goligorsky M. Laser Doppler flowmetry detection of endothelial dysfunction in end-stage renal disease patients: correlation with cardiovascular risk. Kidney Int 70: 1: 157-164, 2006.

46. Laurent S, Boutouyrie P. Arterial stiffness: a new surrogate end point for cardiovascular disease? J Nephrol 20: 6: S45, 2007.

47. Lawrence JE, Ray CA, Carter JR. Vestibulosympathetic reflex during the early follicular and midluteal phases of the menstrual cycle. Am J Physiol Endocrinol Metab 294: 6: E1046-50, 2008.

48. Lazzè MC, Pizzala R, Perucca $\mathbf{P}$, Cazzalini O, Savio M, Forti L, Vannini V, Bianchi L. Anthocyanidins decrease endothelin-1 production and increase endothelial nitric oxide synthase in human endothelial cells. Molecular Nutrition \& Food Research 50: 1: 44-51, 2006.

49. Levenson J, Pessana F, Gariepy J, Armentano R, Simon A. Gender differences in wall shear-mediated brachial artery vasoconstriction and vasodilation. J Am Coll Cardiol 38: 6: 1668-1674, 2001. 
50. Lindstedt IH, Edvinsson M, Evinsson L. Reduced responsiveness of cutaneous microcirculation in essential hypertension-a pilot study. Blood Press 15: 5: 275-280, 2006.

51. Lipa JE, Neligan PC, Perreault TM, Baribeau J, Levine RH, Knowlton RJ, Pang CY. Vasoconstrictor effect of endothelin-1 in human skin: role of ETA and ETB receptors. Am J Physiol 276: 2 Pt 2: H359-67, 1999.

52. Luscher TF, Vanhoutte PM. Endothelium-dependent responses in human blood vessels. Trends Pharmacol Sci 9: 5: 181-184, 1988.

53. 53. Miner JA, Martini ER, Smith MM, Brunt VE, Kaplan PF, Halliwill JR, Minson CT. Short-term oral progesterone administration antagonizes the effect of transdermal estradiol on endothelium-dependent vasodilation in young healthy women. Am J Physiol Heart Circ Physiol 301: 4: H1716-22, 2011.

54. Minson CT, Berry LT, Joyner MJ. Nitric oxide and neurally mediated regulation of skin blood flow during local heating. J Appl Physiol 91: 4: 1619-1626, 2001.

55. Minson CT, Halliwill JR, Young TM, Joyner MJ. Influence of the menstrual cycle on sympathetic activity, baroreflex sensitivity, and vascular transduction in young women. Circulation 101: 8: 862-868, 2000.

56. Moncada S, Vane JR. Pharmacology and endogenous roles of prostaglandin endoperoxides, thromboxane A2, and prostacyclin. Pharmacol Rev 30: 3: 293-331, 1978.

57. Mozaffarian D, Benjamin EJ, Go AS, Arnett DK, Blaha MJ, Cushman M, de Ferranti S, Despres JP, Fullerton HJ, Howard VJ, Huffman MD, Judd SE, Kissela BM, Lackland DT, Lichtman JH, Lisabeth LD, Liu S, Mackey RH, Matchar DB, McGuire DK, Mohler ER,3rd, Moy CS, Muntner P, Mussolino ME, Nasir K, Neumar RW, Nichol G, Palaniappan L, Pandey DK, Reeves MJ, Rodriguez CJ, Sorlie PD, Stein J, Towfighi A, Turan TN, Virani SS, Willey JZ, Woo D, Yeh RW, Turner MB. Heart disease and stroke statistics-2015 update: a report from the american heart association. Circulation 131: 4: e29-e322, 2015.

58. Nuedling S, Eickels Mv, Alléra A, Doevendans P, Meyer R, Vetter H, Grohé C. 17 $\beta$-Estradiol regulates the expression of endothelin receptor type B in the heart. Br J Pharmacol 140: 1: 195-201, 2003. 
59. Palmer RM, Ferrige A, Moncada S. Nitric oxide release accounts for the biological activity of endothelium-derived relaxing factor. 1987.

60. Pedersen SH, Nielsen LB, Mortensen A, Nilas L, Ottesen B. Progestins oppose the effects of estradiol on the endothelin-1 receptor type B in coronary arteries from ovariectomized hyperlipidemic rabbits. Menopause 15: 3: 503-510, 2008.

61. Pickering TG, Hall JE, Appel LJ, Falkner BE, Graves J, Hill MN, Jones DW, Kurtz T, Sheps SG, Roccella EJ. Recommendations for blood pressure measurement in humans and experimental animals: Part 1: blood pressure measurement in humans: a statement for professionals from the Subcommittee of Professional and Public Education of the American Heart Association Council on High Blood Pressure Research. Hypertension 45: 1: 142-161, 2005.

62. Polderman KH, Stehouwer CD, van Kamp GJ, Dekker GA, Verheugt FW, Gooren LJ. Influence of sex hormones on plasma endothelin levels. Ann Intern Med 118: 6: 429-432, 1993.

63. Polderman KH, Stehouwer CD, van Kamp GJ, Schalkwijk CG, Gooren LJ. Modulation of plasma endothelin levels by the menstrual cycle. Metab Clin Exp 49: 5: 648-650, 2000.

64. Rajendran P, Rengarajan T, Thangavel J, Nishigaki Y, Sakthisekaran D, Sethi G, Nishigaki I. The vascular endothelium and human diseases. International journal of biological sciences 9: 10: 1057, 2013.

65. Rubanyi GM. Endothelium-derived relaxing and contracting factors. $J$ Cell Biochem 46: 1: 27-36, 1991.

66. Rubanyi GM, Botelho LH. Endothelins. FASEB J 5: 12: 2713-2720, 1991.

67. Sandoo A, van Zanten JJ, Metsios GS, Carroll D, Kitas GD. The endothelium and its role in regulating vascular tone. Open Cardiovasc Med J 4: 302-312, 2010.

68. Scott-Burden T, Vanhoutte PM. The endothelium as a regulator of vascular smooth muscle proliferation. Circulation 87: 5 SUPPL. V: V51V55, 1993.

69. Seals D, Jablonski K, Donato A. Aging and vascular endothelial function in humans. Clin Sci 120: 357-375, 2011. 
70. Sitia S, Tomasoni L, Atzeni F, Ambrosio G, Cordiano C, Catapano A, Tramontana S, Perticone F, Naccarato P, Camici P. From endothelial dysfunction to atherosclerosis. Autoimmunity reviews 9: 12: 830-834, 2010.

71. Stachenfeld NS, Taylor HS. Challenges and methodology for testing young healthy women in physiological studies. Am J Physiol Endocrinol Metab 306: 8: E849-53, 2014.

72. Stamler JS, Loh E, Roddy MA, Currie KE, Creager MA. Nitric oxide regulates basal systemic and pulmonary vascular resistance in healthy humans. Circulation 89: 5: 2035-2040, 1994.

73. Stauffer BL, Westby CM, Greiner JJ, Van Guilder GP, Desouza CA. Sex differences in endothelin-1-mediated vasoconstrictor tone in middleaged and older adults. Am J Physiol Regul Integr Comp Physiol 298: 2: R261-5, 2010.

74. Stewart J, Kohen A, Brouder D, Rahim F, Adler S, Garrick R, Goligorsky MS. Noninvasive interrogation of microvasculature for signs of endothelial dysfunction in patients with chronic renal failure. $A m J$ Physiol Heart Circ Physiol 287: 6: H2687-96, 2004.

75. Taddei S, Ghiadoni L, Virdis A, Versari D, Salvetti A. Mechanisms of endothelial dysfunction: clinical significance and preventive nonpharmacological therapeutic strategies. Curr Pharm Des 9: 29: 2385-2402, 2003.

76. Terenghi G, Bull H, Bunker C, Springall D, Zhao Y, Wharton J, Dowd P, Polak J. Endothelin-1 in human skin: immunohistochemical, receptor binding, and functional studies. J Cardiovasc Pharmacol 17: S467-470, 1991.

77. Thijssen DH, Black MA, Pyke KE, Padilla J, Atkinson G, Harris RA, Parker B, Widlansky ME, Tschakovsky ME, Green DJ. Assessment of flow-mediated dilation in humans: a methodological and physiological guideline. Am J Physiol Heart Circ Physiol 300: 1: H2-12, 2011.

78. Tostes R, Nigro D, Fortes Z, Carvalho M. Effects of estrogen on the vascular system. Brazilian Journal of Medical and Biological Research 36: 9: 1143-1158, 2003.

79. Vanhoutte PM, Rubanyi GM, Miller VM, Houston DS. Modulation of vascular smooth muscle contraction by the endothelium. Annu Rev Physiol 48: 1: 307-320, 1986. 
80. Verma S, Anderson TJ. Fundamentals of endothelial function for the clinical cardiologist. Circulation 105: 5: 546-549, 2002.

81. Vita JA, Keaney JF. Endothelial function: a barometer for cardiovascular risk? Circulation 106: 6: 640-642, 2002.

82. Wagner OF, Christ G, Wojta J, Vierhapper H, Parzer S, Nowotny PJ, Schneider B, Waldhausl W, Binder BR. Polar secretion of endothelin-1 by cultured endothelial cells. J Biol Chem 267: 23: 16066-16068, 1992.

83. Weksler BB, Marcus AJ, Jaffe EA. Synthesis of prostaglandin I2 (prostacyclin) by cultured human and bovine endothelial cells. Proc Natl Acad Sci U S A 74: 9: 3922-3926, 1977.

84. Wenner MM, Taylor HS, Stachenfeld NS. Endothelin B receptor contribution to peripheral microvascular function in women with polycystic ovary syndrome. J Physiol 589: Pt 19: 4671-4679, 2011.

85. Widlansky ME, Gokce N, Keaney JF, Vita JA. The clinical implications of endothelial dysfunction. J Am Coll Cardiol 42: 7: 1149-1160, 2003.

86. Wong BJ, Fieger SM. Transient receptor potential vanilloid type 1 channels contribute to reflex cutaneous vasodilation in humans. $J \mathrm{Appl}$ Physiol 112: 12: 2037-2042, 2012.

87. Yanagisawa M, Kurihara H, Kimura S, Tomobe Y, Kobayashi M, Mitsui Y, Yazaki Y, Goto K, Masaki T. A novel potent vasoconstrictor peptide produced by vascular endothelial cells. Nature 332: 6163: 411-415, 1988. 


\section{Appendix A}

\section{IRB APPROVAL LETTER}

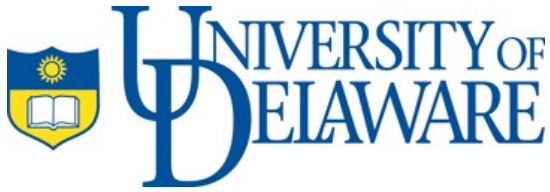

Research Office

210 Hullihen Hall

University of Delaware

Newark, Delaware 19716-1551

Ph: 302/831-2136

Fax: $302 / 831-2828$

DATE:

June 3, 2015

TO:

Megan Wenner, PhD

FROM:

University of Delaware IRB

STUDY TITLE:

[385453-15] Mechanisms of microvascular dysfunction in women SUBMISSION TYPE:

Amendment/Modification

ACTION:

APPROVED

APPROVAL DATE:

June 3, 2015

EXPIRATION DATE:

November 13, 2015

REVIEW TYPE:

Expedited Review

REVIEW CATEGORY: Expedited review category \# (45 CRF 46.110 (b) (2)

Thank you for your submission of Amendment/Modification materials for this research study. The University of Delaware IRB has APPROVED your submission. This approval is based on an appropriate risk/benefit ratio and a study design wherein the risks have been minimized. All research must be conducted in accordance with this approved submission.

This submission has received Expedited Review based on the applicable federal regulation.

Please remember that informed consent is a process beginning with a description of the study and insurance of participant understanding followed by a signed consent form. Informed consent must continue throughout the study via a dialogue between the researcher and research participant. Federal regulations require each participant receive a copy of the signed consent document.

Please note that any revision to previously approved materials must be approved by 
this office prior to initiation. Please use the appropriate revision forms for this procedure.

All SERIOUS and UNEXPECTED adverse events must be reported to this office. Please use the appropriate adverse event forms for this procedure. All sponsor reporting requirements should also be followed.

Please report all NON-COMPLIANCE issues or COMPLAINTS regarding this study to this office. Please note that all research records must be retained for a minimum of three years.

Based on the risks, this project requires Continuing Review by this office on an annual basis. Please use the appropriate renewal forms for this procedure.

If you have any questions, please contact Nicole Farnese-McFarlane at (302) 8311119 or nicolefm@udel.edu. Please include your study title and reference number in all correspondence with this office. 


\section{Appendix B}

\section{WESTERN BLOT PROCEDURE}

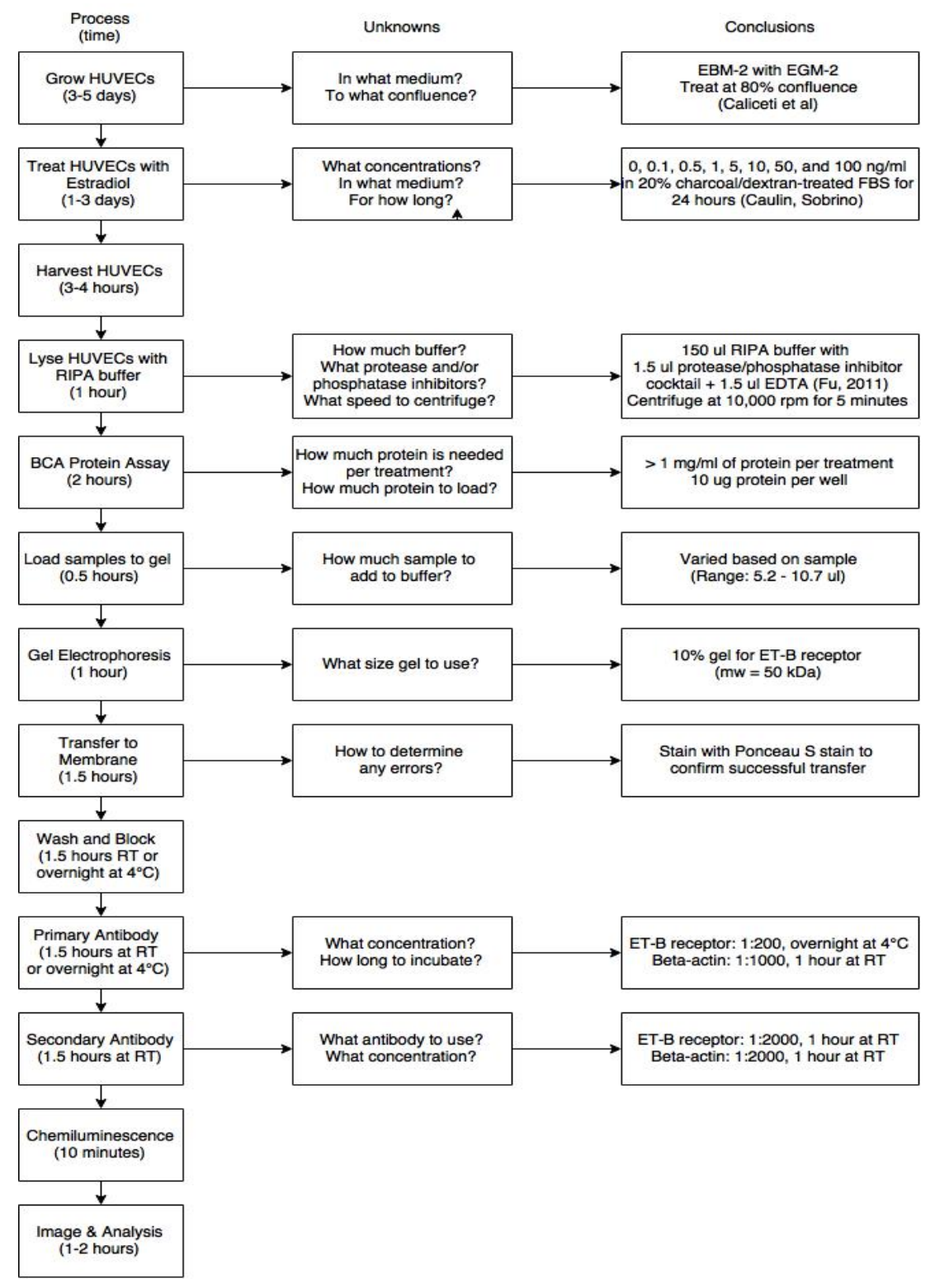

